\title{
Diferenciação morfológica das espécies de peixes-rei, Odontesthes Evermann \& Kendall (Osteichthyes, Atherinopsidae) no extremo sul do Brasil: morfometria multivariada
}

\author{
Marlise de Azevedo Bemvenuti ${ }^{1}$
}

\begin{abstract}
Morphological variation in the species of silverside Odontesthes Evermann \& Kendall (Osteichthyes, Atherinopsidae) in the Southern Brazil: a multivariate morphometry. The systematic relationships in the species of the genus Odontesthes Evermann \& Kendall, 1906 were analysed by multivariate morphometry, using data adjusted for alometric size effects by orthogonal projections. The results are discussed in terms of morphological differentiation to each geographic units. It was concluded that seven species were identified in the southern Brazilian coast. Five of them inhabit freshwater environments, $O$. bonariensis (Valenciennes, 1835), O. humensis De Buen, 1953, O. retropinnis (De Buen, 1953), O. aff. perugiae Evermann \& Kendall, 1906 and $O$. mirinensis Bemvenuti, 1995. The freshwater atherinids with the largest body size, $O$. retropinnis, $O$. bonariensis and $O$. humensis, can be distinguished by snout size, mouth position and number of gill rakers on the first branchial arch. The small size silversides. Odontesthes aff. perugiae and $O$. mirinensis, showed features of similar morphologic and sympatric distribution. The remaining species were represented by $O$. incisa (Jenyns, 1842), that occurred in coastal areas and $O$. argentinensis (Valenciennes, 1835) in brackish waters. In the last species, intraespecific morphological variation is attributed to phenotypic plasticity, resulted from environmental conditions found in that ecosystem.
\end{abstract}

KEY WORDS. Odontesthes, systematic relationships, multivariate morphometry, Southern Brazilian

A família Atherinopsidae Saeed, Ivantsoff \& Crowley, 1994, compreende os peixes-rei do Novo Mundo, Menidiinae e Atherinopsinae. Dos seis gêneros descritos na sub-família Atherinopsinae, apenas dois são sul-americanos (DYER 1996), Basilichthys Girardi, 1854 e Odontesthes Evermann \& Kendall, 1906, caracterizados pela presença de arcos hemais especializados e elevada contagem vertebral (SAEED et al. 1994).

O gênero Odontesthes Evermann \& Kendall, 1906, foi criado com base em caracteres pouco precisos, evidentes apenas na espécie-tipo-O. perugiae Evermann \& Kendall, 1906. Os autores que os seguiram não reconheceram o gênero Odontesthes, mantendo as classificações mais antigas de Atherina Linnaeus, 1758, Atherinichthys Bleeker, 1853 e Chirostoma Swainson, 1839. Posteriormente, MIRANDA RIBEIRO (1915) descreveu Pseudothyrina jheringi, coletado na costa do Rio Grande

1) Departamento de Oceanografia, Laboratório de Ictiologia, Campus Carreiros, Fundaçāo Universidade Federal do Rio Grande. Caixa Postal 474, 96201-900 Rio Grande, Rio Grande do Sul, Brasil. E-mail docmab @ super.furg.br

Revta bras. Zool. 19 (1): $251-287.20$ ก 
do Sul e Kronia iguapensis em Iguape, São Paulo (Brasil). Esta última teve como caráter diagnóstico "as ventrais unidas entre si", um caráter sem muita consistência como se observou mais tarde (SCHULTZ 1948, BEMVENUTI 1993). JORDAN \& HUBBS (1919) resgataram o gênero Odontesthes, caracterizando-o com "prémaxilares protráteis", em distinção a Basilichthys, incluindo no gênero, as espécies $O$. platensis (Berg, 11895), O. perugiae Evermann \& Kendall, 1906 e O. argentinensis (Valenciennes, 1835).

DE Buen (1953) recuperou o status genérico de Kronia Miranda Ribeiro, por considerar importante a estrutura das "ventrais unidas entre si", esquecida pela maioria dos autores, incluindo novas espécies, K. alba De Buen, 1953 e K. rex De Buen, 1953. Nesta mesma ocasião também descreveu O. humensis De Buen, 1953, O. guazu De Buen, 1953 e Yaci retropinnis De Buen, 1953, todas com localidadetipo no Uruguai.

Risso \& Risso (1953) apresentaram um novo gênero, Sorgentinia (espécietipo Atherina incisa Jenyns, 1842), desconhecendo o trabalho de MARRERO (1950), que criou Austroatherina (sem designação de espécie-tipo). O caráter importante na formação do novo gênero Sorgentinia, foi a ausência de expansões laterais, nos arcos hemais das vértebras.

WHITE (1985), num trabalho de revisão filogenética da sub-família Atherinopsinae, reconheceu dois grupos de peixes-rei sul-americanos, Odontesthes para a costa do Atlântico e parte do Pacífico Sul (Peru) e Basilichthys somente para a costa do Pacífico. Em ambos a bexiga natatória estende-se em um funil hemal, formado pela expansão lateral dos arcos hemais.

Odontesthes possui caracteres através dos quais pode ser reconhecido, mesetmóide ausente, boca protrátil, cabeça do palatino com uma plataforma óssea mediana, processo ventral do nasal em contato com o lacrimal, etmóide lateral com protuberância óssea ventral, basioccipital sulcado e fenestrado, opérculo fenestrado no ângulo anterodorsal interno, ligamento de Baudelot ossificado (dois espinhos finos presos à base do crânio), 9 a 10 vértebras caudais expandidas com paredes alargadas formando um tubo hemal (urosoma), por onde se prolonga a bexiga natatória (WHITE 1985; DYER 1996).

As espécies de Odontesthes têm sido tradicionalmente identificadas através de caracteres morfo-merísticos. A ineficácia de alguns desses caracteres, é demonstrada através de freqüentes mudanças na classificação de suas espécies, auxiliada pela grande semelhança entre os peixes-rei. Recentemente, a utilização de técnicas estatísticas, denominadas morfometria multivariada, tem sido empregadas para evidenciar a diferenciação da forma do corpo em relação ao tamanho dos peixes, permitindo que as relações entre indivíduos ou grupos possam ser mais facilmente detectadas e interpretadas (PIMENTEL 1979; REYMENT et al. 1984; BOOKSTEIN et al. 1985; REIS et al. 1987; REIS 1988; ROHLF 1990; BEMVENUTI 1993, 1995). Diferenças morfológicas também podem ser utilizadas para definir unidades geográficas inf ra-específicas (ROHLF \& BOOKSTEIN 1987; DUARTE et al. 1998; BEMVENUTI 2000). Em geral, a técnica mais utilizada é a análise dos componentes principais, que avalia a variação morfométrica "dentro do grupo" e sua relação "entre os grupos", procurando detectar a diferenciação fenotípica (REIS 1988). A 
redescrição de O. argentinensis (BEMVENUTI 1993), a descrição de uma nova espécie, $O$. mirinensis Bemvenuti, 1995 e a diferenciação geográfica de $O$. argentinensis (BEMVENUTI 2000) comprovaram a importância na delimitação dos caracteres e sua utilização na morfometria multivariada, permitindo esclarecer a diferenciação morfológica e geográfica das espécies de peixes-rei.

Algumas das espécies de peixes-rei são de grande porte, podendo alcançar entre 300 e $500 \mathrm{~mm}$ de comprimento total, sendo de grande importância na pesca artesanal da região e muito utilizadas em aquicultura, o que sugere um especial interesse pelo seu estudo biológico. O objetivo deste trabalho foi definir os grupos de espécie de peixes-rei que ocorrem no extremo sul do Brasil, através da morfometria multivariada, a partir do qual poderão ser obtidas diagnoses e analisados os padrões de diferenciação geográfica

\section{MATERIAL E MÉTODOS}

\section{Descrição da área de estudo}

A Planície Costeira do Estado do Rio Grande do Sul, no extremo Sul do Brasil, é constituída por um enorme sistema lagunar (Lagoa dos Patos e Lagoa Mirim) e uma série de outras lagoas menores, originadas em sucessivos ciclos de transgressão e regressão, ocorridos a partir do Pleistoceno Inf erior (DELANEY 1965; VILLWOCK 1984, 1988) (Fig. 1).

A Lagoa dos Patos, com $10.360 \mathrm{~km}^{2}$ de superfície, é a laguna mais extensa da América do Sul (DELANEY 1965). O corpo da laguna, onde são encontradas cidades de médio porte tais como São Lourenço do Sul, Camaquã e Tapes, estende-se desde Itapoã, Porto Alegre, até o local denominado Ponta da Feitoria (Pelotas). A parte inferior, com características nitidamente estuarinas, corresponde a $10 \%$ de sua área total e estende-se desde a Ponta da Feitoria até a desembocadura, nos Molhes da Barra de Rio Grande. Nesta área são encontradas pequenas enseadas rasas, oligohalinas, denominadas sacos, com profundidade máxima de três metros. A Lagoa dos Patos comunica-se com a Lagoa Mirim, ao sul da cidade de Rio Grande, através do Canal São Gonçalo. A Lagoa Mirim possui em média $195 \mathrm{~km}$ de comprimento e $22 \mathrm{~km}$ de largura, ocupando uma área de $3.749 \mathrm{~km}^{2}$, dos quais $2.382 \mathrm{~km}^{2}$ estão em território brasileiro. Localiza-se entre $32^{\circ} 10^{\prime}$ e $33^{\circ} 37^{\prime} \mathrm{S}$, sendo formada por um amplo sistema de banhados, como é o caso do banhado do Taim, atualmente uma Estação Ecológica.

Outras lagoas de menor tamanho são litorâneas e estão dispostas ao longo da linha de costa, denominadas "lagoas em rosário" (VILLWOCK 1987). A maior delas é a Lagoa Mangueira, um corpo de água doce fechado, situada entre os paralelos $32^{\circ} 45^{\text {' }}$ e $33^{\circ} 32^{\prime}$ S. Ocupa uma área estimada em cerca de $800 \mathrm{~km}^{2}$, com aproximadamente $100 \mathrm{~km}$ de comprimento, $11,5 \mathrm{~km}$ na máxima largura e $7,4 \mathrm{~m}$ de profundidade média (DELANEY 1965). As demais "lagoas em rosário" ficam ao norte do Estado, entre Cidreira e Torres. São na maioria das vezes, lagoas rasas, com cerca de dois a três metros de profundidade, Lagoa Fortaleza, Cerquinha, Cidreira, Custódias, Armazém, Tramandai e outras menores. Na área setentrional da costa do Rio Grande do Sul, existem três lagoas de médio porte, Lagoa dos Barros, dos Quadros e Itapeva. São lagoas fechadas com uma profundidade média que oscila entre quatro e sete metros, cuja área individual é de cerca de $100 \mathrm{~km}^{2}$ (DELANEY 1965). 


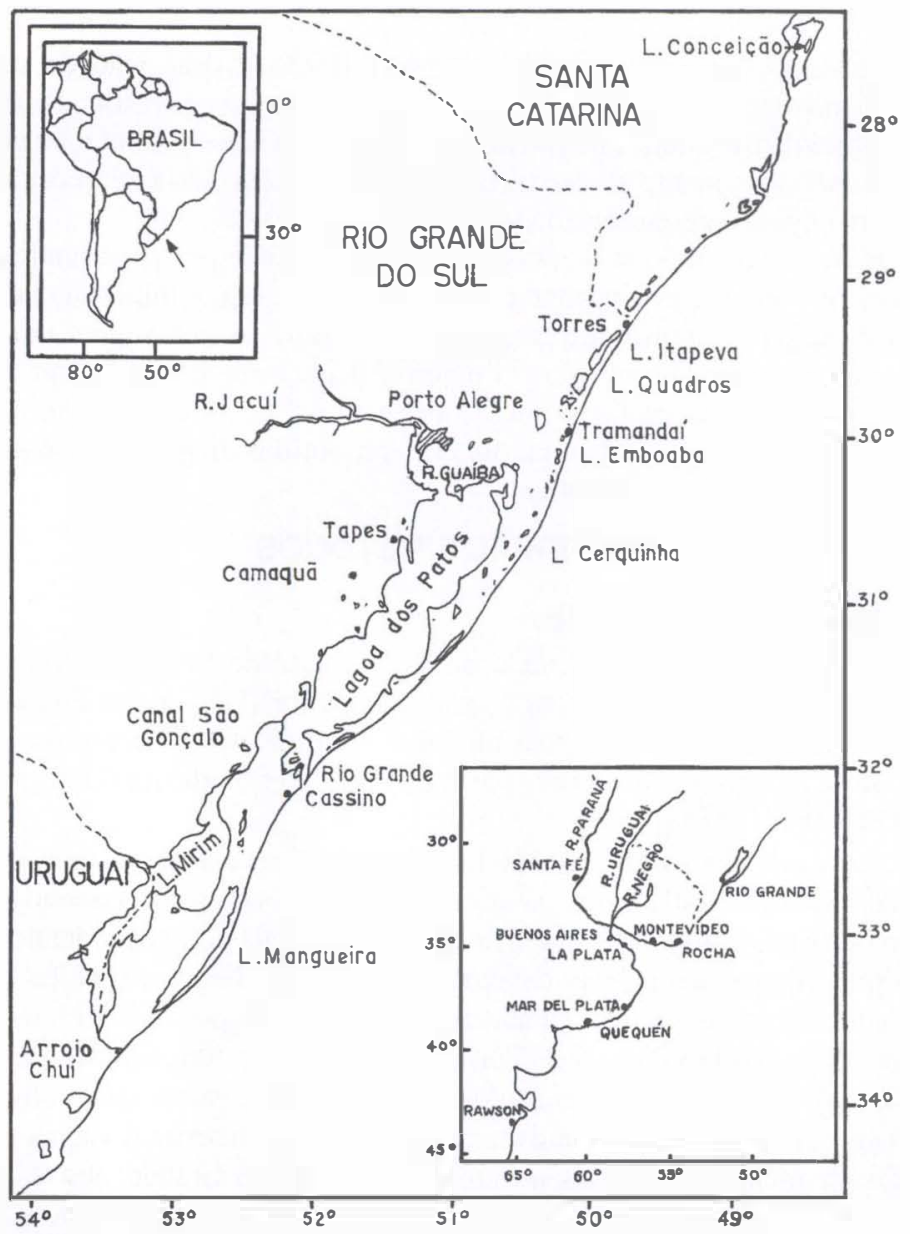

Fig. 1. Área de distribuiçāo das espécies de peixes-rei no extremo sul da América do Sul.

\section{Obtenção dos dados morfológicos}

Foram obtidas 25 variáveis morfométricas, medidas com paquímetro de 0,1 $\mathrm{mm}$ de precisão e 11 caracteres merísticos. Para cada espécie foram apresentadas tabelas com as proporções corporais médias, limites de amplitude, desvio, coeficiente de variação (cv = desvio/média*100), além dos caracteres merísticos.

As variáveis morfométricas são: (cp) comprimento padrão; (pd1, pd2, pan, pp1, pp2) distâncias anteriores às nadadeiras dorsal 1, dorsal 2, anal, peitoral e pélvica; (cab) comprimento da cabeça; (altcab) altura máxima da cabeça; (foc) comprimento do focinho; (olho) diâmetro horizontal do olho; (intorb) distância inter-orbital; (boca) largura da boca; (max) comprimento da maxila; (altped) altura mínima do pedúnculo caudal; ( 1 lp2, dld2) distâncias entre as origens da peitoral e pélvica e das dorsais; (pl pc, p2pc, anpc, d l pc, d2pc) distâncias entre as origens das 
nadadeiras e o pedúnculo caudal; (andl, and2, anpl, anp2) distâncias entre as origens da anal e demais nadadeiras (Fig. 2). Os caracteres merísticos são: (d1 ,d2, an, pl) número de espinhos ou raios das nadadeiras dorsais, anal e peitoral; (and2) número de raios da nadadeira anal, anteriores ao início da segunda dorsal; (eslong) número de escamas da linha longitudinal, contadas acima da faixa prateada; (espdl) número de escamas anteriores a primeira dorsal; (esped) número de escamas ao redor do pedúnculo caudal; (brqs, brqi, brqt) número de rastros superiores, inferiores e totais do primeiro arco branquial (o rastro do ângulo está incluído na contagem dos rastros inferiores).

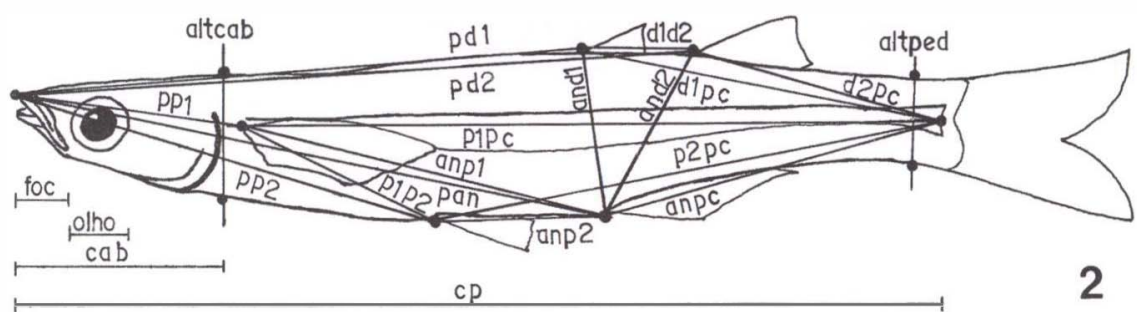

Fig. 2. Diagrama de medidas utilizadas na morfometria das espécies de Odontesthes.

\section{Análise Multivariada}

A análise dos componentes principais foi empregada para detectar variações em caracteres quantitativos e avaliar padrões de discriminação entre os diferentes locais amostrados (NEFF \& MARCUS 1980, REIS 1988, MARCUS 1990). A diferenciação morfológica foi investigada a partir da matriz de variância-covariância dos caracteres morfométricos, transformados em logaritmos decimais. A transformação foi necessária para normalizar a distribuição dos dados e homogeneizar as variâncias (SOKAL \& ROHLF 1981; MOSIMANN \& JAMES 1979; BOOKSTEIN et al. 1985). O primeiro eixo na análise dos componentes principais $(\mathrm{cpl})$ tem sido, seguidamente interpretado como fator de tamanho geral, quando todos os seus coef icientes possuem o mesmo sinal, valores de semelhante magnitudes, além da maior variância, que é atribuída às diferenças em tamanho dos indivíduos. Os componentes 2 e 3 expressam variações na forma, apresentando coeficientes com sinais diferentes e valores variados. Coef icientes alométricos multivariados podem ser interpretados como coeficientes de crescimento relativo, sendo calculados a partir da divisão de cada coeficiente do primeiro eixo, pela média dos coeficientes deste eixo (JOLICOEUR 1963). Quando existe alometria os valores dos coeficientes são diferentes da unidade (1), desviando-se do vetor isométrico teórico (MORRISON 1976). Caracteres com alometria positiva aumentam em tamanho mais rapidamente do que os demais caracteres, enquanto os com alometria negativa crescem mais lentamente do que os demais.

A variação no tamanho dos peixes, em função dos diferentes estágios de crescimento, pode confundir a interpretação dos resultados na análise de diferenciação morfológica, principalmente quando estiverem relacionados com variação geográfica, sendo aconselhável o uso de técnicas que removam o efeito do fator 
tamanho (ROHLF \& BOOKSTEIN 1987; DuARTE et al. 1998). Para retirar esta influência, os dados foram ajustados através do método das projeções ortogonais, descrito por BURNABY (1966). Este procedimento exclui o primeiro vetor (cpl), da matriz de variância-covariância, projetando os dados restantes num subespaço ortogonal independente do vetor tamanho (ROHLF \& BOOKSTEIN 1987; DUARTE et al. 1998). Os novos componentes principais (CP1 e CP2) terão então, coeficientes com sinais positivos e negativos e valores variados, sendo indicadores de diferenças na forma dos organismos estudados (Jolicoeur \& MOSIMANN 1960; NEFF \& MARCUS 1980; REYMENT et al. 1984; BOOKSTEIN et al. 1985; REIS 1988).

O processamento dos dados foi efetuado através do programa NTSYS-pc (ROHLF 1994) para microcomputadores. Os peixes-rei analisados encontram-se depositados na coleção da Fundação Universidade Federal do Rio Grande (FURG), Laboratório de Ictiologia, de acordo com a listagem em "Material examinado".

\section{RESULTADOS E DISCUSSÃO}

No extremo Sul do Brasil foram reconhecidas sete espécies de peixes-rei do gênero Odontesthes. Na região do estuário da Lagoa dos Patos e área costeira marinha ocorre $O$. argentinensis e na plataforma interna, com menor freqüência ocorre $O$. incisa. As demais espécies ocorrem em ambientes de água doce, $O$. bonariensis, $O$. humensis, $O$. retropinnis, $O$. perugiae e $O$. mirinensis. Outras espécies são descritas para o gênero, mas não ocorrem nesta região, como é o caso de O. platensis, O. smitti (Lahille, 1929) e O. nigricans (Richardson, 1848), naturais de águas mais frias, na costa do Uruguai e Argentina e O. regia (Humboldt, 1821), em ambientes de água doce do Chile e Peru (LAHILle 1929).

A seguir, são apresentadas para cada espécie, a diagnose e descrição, sendo discutidas a distribuição geográfica e variação intra-específica.

\section{Odontesthes argentinensis (Valenciennes, 1835)}

Fig. 3A, Tab. I

Atherina argentinensis Valenciennes, 1835: 350 In: Cuvier \& Valenciennes (localidade-tipo: Montevideo, Uruguay).

Kronia iguapensis Miranda Ribeiro, 1915 (localidade-tipo: Iguape, São Paulo,Brasil).

Pseudothyrina jheringi Miranda Ribeiro, 1915 (localidade-tipo: Rio Grande do Sul, Brasil).

Kronia alba De Buen, 1953: 59 (localidade-tipo: Laguna de Rocha, Uruguai).

Kronia rex De Buen, 1953: 64 (localidade-tipo: La Paloma, Rocha, Uruguai).

Odontesthes argentinensis; Hubbs, 1917: 308; Jordan \& Hubbs, 1919: 64; De Buen, 1950: 100; Bemvenuti, 1993: 29.

Material examinado. Holótipo de Kronia iguapensis: MNRJ 1351 (217,5 mm cp) Iguape, São Paulo, Brasil; síntipos de Pseudothyrina jheringi: MNRJ 2369 (265 mm, 270 mm cp) Rio Grande do Sul, Brasil, 5-VII-1908; holótipo de Kronia alba: MHNM 1801 (122 mm cp) e parátipo MHNM 1802 (77,5 mm cp) Laguna de Rocha, Departamento de Rocha, Uruguay; holótipo de Kronia rex: MHNM 1803 ( $140 \mathrm{~mm} \mathrm{cp)} \mathrm{La} \mathrm{Paloma,} \mathrm{Departamento} \mathrm{de} \mathrm{Rocha,} \mathrm{Uruguay;} \mathrm{síntipos} \mathrm{de} \mathrm{Atherina}$ argentinensis: MNHN A.4362 (139,7 mm, 132,7 mm, 141,3 mm cp) A.4363 (136,3 $\mathrm{mm}, 139,5 \mathrm{~mm} \mathrm{cp}$ ) Montevideo, Uruguay (somente dados biométricos). 

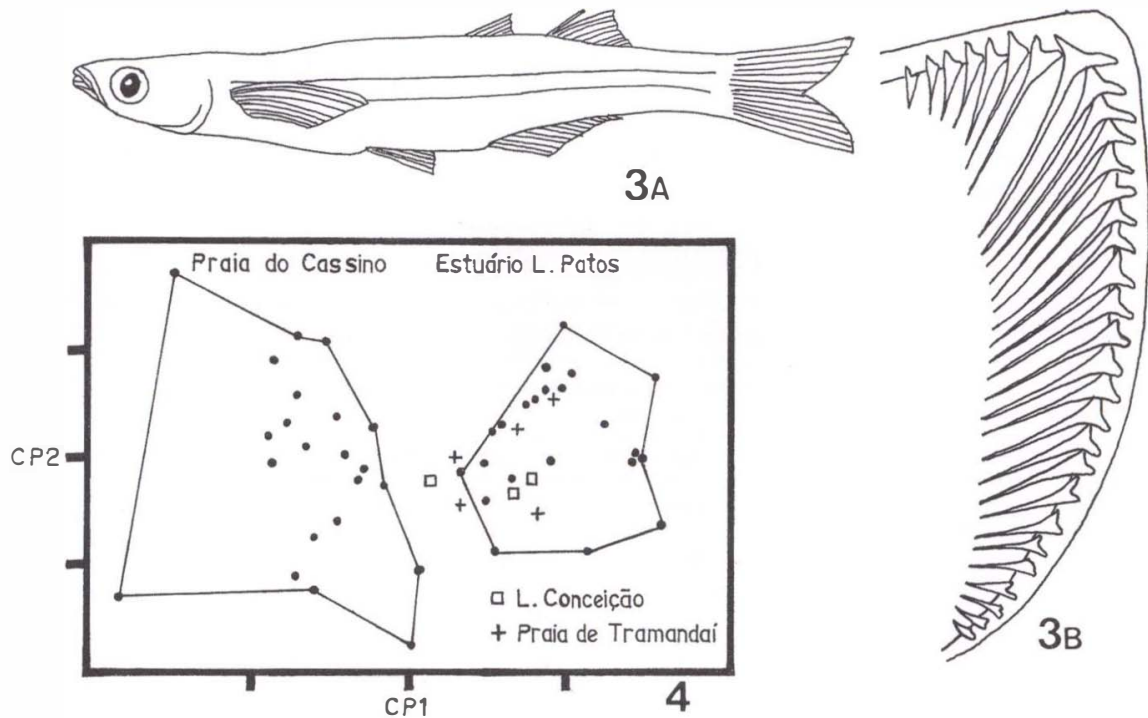

Figs 3-4. (3) exemplar de Odontesthes argentinensis,

FURG nāo catalogado, estuário da Lagoa dos Patos, Rio Grande do Sul, julho de 1987, (B) primeiro arco branquial esquerdo; (4) Projeção dos escores individuais de 59 exemplares de O. argentinensis; no espaço dos dois primeiros componentes principais (CP1, CP2), para 25 caracteres morfométricos; dados ajustados com projeçōes ortogonais de Bumaby.

Outros espécimens examinados. BRASIL, Rio Grande do Sul: FURG 81.0005 (4) Rio Grande, 31 out 1980; FURG 82.0045 (7) Praia do Cassino, Farol do Sarita, fev 1982; FURG 83.0044 (1) Praia do Cassino, 15 ago 1983; FURG 86.0004 (13) $25 \mathrm{~km}$ ao sul da Praia do Cassino, 11 set 1986; FURG 86.0005 (11) idem, 12 set 1986; FURG 86.0006 (13) 8 km ao sul da Praia do Cassino, 23 jul 1986; FURG 86.0007 (7) $25 \mathrm{~km}$ ao sul da Praia do Cassino, 22 nov 1986; FURG 86.0008 (4) Praia do Cassino, 25 set 1986; FURG 86.0009 (6) 25 km ao sul da Praia do Cassino, 3 set 1986; FURG 86.0010 (2) 6 km ao sul da Praia do Cassino, 23 jul 1986; FURG 86.0011 (12) Ponta da Marambaia, Rio Grande, 3 jul 1986; FURG 86.0012 (12) Saco do Justino, Rio Grande, 8 ago 1986; FURG 86.0013 (5) idem, jul 1986; FURG 86.0014 (9) Ponta dos Pescadores, Rio Grande, 2 out 1986; FURG 86.0020 (3) Praia de Tramandai, 7 jul 1986; FURG 87.0010 (5) Praia do Cassino, 17 jun 1987; FURG 87.0011 (2) Praia do Cassino, 4 ago 1987; FURG 87.0012 (7) idem, 31 ago 1987; FURG 87.0014 (15) Rio Grande, out 1987; FURG 87.0015 (5) idem, 28 jan 1987; FURG 87.0016(2) ibidem, 21 jul 1987; FURG 87.0029 (2) Praia de Tramandai, 12 ago 1987; FURG 88.0001 (4) Saco do Justino, Rio Grande, 27 set 1988; MCP 5545, 5546, 5547 (3) Saco do Arraial Rio Grande, 25 out 1970; MCP 4487 (1), MCP 4494 a 4525 (32) Mostardas, 28 jan 1970; MCP 5393 e 5394 Praia do Cassino, 25 out 1970. Santa Catarina: FURG 91.0001 (1) Lagoa da Conceição, Florianópolis, 27 set 1991; FURG 91.0002 (1) idem, 27 jul 1988; FURG 92.0001 (1) ibidem, 16 abr 1992; MCP 4935 (1) e 4974 (1) Ponta das Canas, Florianópolis, 21 jul 1970; MCP 5271, 5272, 5274, 5275 (4) Lagoa da Conceição, Florianópolis, 24 jul 1970; MCP 5567 e 5568 (2) Ponta das Canas, Florianópolis, 6 dez 1970. ArgentinA: MLP 
5.XI.45.3 (18) Quequén Salado, La Plata, 5 nov 1945; MLP 24.XI.33.1 (24) Quequén, La Plata, 24 nov 1933; MLP 1.V.52.16 (14) Pedro Luro, La Plata, 1 mai 1952; MLP 1.II I.48.14 (14) Monte Hermoso, La Plata, 1 mar 1948: MLP 7.III.34.12 (7) Quequén, La Plata, 7 mar 1934.

Tabela I. Dados comparativos dos caracteres morfométricos e merísticos de quatro populaçōes de $O$. argentinensis. Medidas expressas como percentagens do comprimento padrão e comprimento da cabeça; (cv) coeficiente de variação; vide texto para demais abreviaturas.

\begin{tabular}{|c|c|c|c|c|c|c|c|c|c|c|c|c|c|c|c|c|}
\hline \multirow[t]{2}{*}{ Variáveis } & \multicolumn{4}{|c|}{$\begin{array}{l}\text { Praia Cassino } \\
\qquad(n=25)\end{array}$} & \multicolumn{4}{|c|}{$\begin{array}{l}\text { Estuário Lagoa dosPatos } \\
\qquad(n=26)\end{array}$} & \multicolumn{4}{|c|}{$\begin{array}{l}\text { Estuário Rio Tramandai } \\
\qquad(n=5)\end{array}$} & \multicolumn{4}{|c|}{$\begin{array}{l}\text { Barra Lagoa Conceiçāo } \\
\qquad(n=3)\end{array}$} \\
\hline & Min & Máx & Méd Des & cv & Min Máx & Méd & Des & cv & Min 1 & Máx $N$ & Méd Des & $\mathrm{cv}$ & Min & Máx 1 & Méd Des & $\mathrm{cv}$ \\
\hline $\mathrm{cp}(\mathrm{mm})$ & 158 & 310 & & & 141274 & & & & 123 & 158 & & & 105 & 152 & & \\
\hline \multicolumn{17}{|c|}{ Percentagens do comprimento padrāo } \\
\hline pd1 & 54,7 & 60,4 & $58,01,63$ & 2,81 & $56,562,3$ & 59,7 & 1,21 & 2,03 & 58,2 & 61,8 & $60,31,28$ & 2,12 & 57,9 & 58,6 & $58,20,29$ & 0,51 \\
\hline pd2 & 68,7 & 74,3 & $71,51,42$ & 1,99 & $71,476,5$ & 74,0 & 1,24 & 1,67 & 74,3 & 75,3 & $\begin{array}{lll}74,8 & 0,35\end{array}$ & 0,47 & 71,7 & 73,6 & $72,4 \quad 0,86$ & 1,19 \\
\hline pan & 58,8 & 65,8 & $62,1 \quad 1,49$ & 2,39 & $61,166,4$ & 63,7 & 1,53 & 2,40 & 62,5 & 65,8 & $64,2 \quad 1,20$ & 1,87 & 62,0 & 64,8 & $63,5 \quad 1,17$ & 1,84 \\
\hline pp1 & 21,6 & 25,7 & $24,10,89$ & 3,75 & $21,824,1$ & 23,0 & 0,65 & 2,82 & 24,3 & 25,7 & $25,10,46$ & 1,82 & 23,0 & 24,8 & $24,0 \quad 0,72$ & 3,02 \\
\hline pp2 & 39,4 & 47.5 & $44,7 \quad 1,93$ & 4,31 & $43,8 \quad 47,8$ & 46,1 & 1,23 & 2,67 & 44,9 & 48,8 & $46,6 \quad 1,35$ & 2,89 & 45,3 & 46,1 & $45,7 \quad 0,30$ & 0,66 \\
\hline$c a b$ & 20,0 & 22 & $21,4 \quad 0,77$ & 3,58 & $20,022,3$ & 21,4 & 0,57 & 2,65 & 22,8 & 22,8 & $22,80,01$ & 0,06 & 21,7 & 22,9 & $22,10,51$ & 2,29 \\
\hline attcab & 10,3 & 13,6 & $11,50,92$ & 7,98 & $12,3 \quad 15,4$ & 13,8 & 0,79 & 5,73 & 13,0 & 13,9 & $13,50,34$ & 2,55 & 12,5 & 13,3 & $13,0 \quad 0,36$ & 2,76 \\
\hline foc & 6,2 & 7,7 & $6,90,37$ & 5,41 & $6,5 \quad 7,5$ & 7,1 & 0,26 & 3,70 & 7,1 & 7,9 & $7,50,28$ & 3,70 & 7,0 & 7,6 & $7,30,24$ & 3,34 \\
\hline altped & 7,1 & 10,4 & $9,40,67$ & 7,10 & $8,6 \quad 10,6$ & 9,7 & 0,51 & 5,25 & 9,8 & 10,3 & $\begin{array}{lll}10,1 & 0,22\end{array}$ & 2,19 & 9,4 & 10,2 & $9,80,34$ & 3,42 \\
\hline p1p2 & 22,0 & 27,0 & $24,1 \quad 1,15$ & 4,80 & $24,0 \quad 28,7$ & 25,9 & 1,11 & 4,25 & 23,5 & 26,3 & $25,0 \quad 1,04$ & 4,15 & 23,4 & 24,8 & $24,2 \quad 0,55$ & 2,29 \\
\hline p1pc & 74,0 & 81,6 & $77,7 \quad 1,79$ & 2,30 & $77,780,9$ & 78,3 & 1,01 & 1,29 & 75,9 & 78,7 & $77,4 \quad 1,01$ & 1,30 & 75,8 & 78,5 & $77,5 \quad 1,23$ & 1,59 \\
\hline p2pc & 4 & 6 & $57,03,25$ & 5,70 & 54,46 & & 1 & 2,79 & 55,9 & 5 & 1 & 1,60 & 58,6 & 59,2 & $59,00,2$ & 0,44 \\
\hline anpc & 37,6 & 42,1 & $39,6 \quad 1,38$ & 3,47 & $25,628,7$ & 27,3 & 0 & 3,04 & 37,7 & 40,43 & $39,20,95$ & 2,41 & 39,8 & 41,4 & $40,4 \quad 0,72$ & 1,79 \\
\hline d1pc & 39,1 & 45,8 & $42,5 \quad 1,65$ & 3,90 & $39,444,8$ & 41,3 & 1,38 & 3,35 & 39,5 & 44,3 & $41,6 \quad 1,80$ & 4,31 & 42,8 & 43,8 & $43,30,43$ & 0,99 \\
\hline d2pc & 26,4 & 32,2 & $29,21,61$ & 5,51 & $25,6 \quad 28,7$ & 2 & & 3,04 & 26,0 & 72 & 50 & 0 & 28,1 & 28,6 & 3,30 & 0 \\
\hline d1d2 & 12,2 & 16,4 & $13,61,04$ & 7,64 & $12,7 \quad 16,4$ & 14,5 & 1,03 & 7,11 & 13,4 & 17,1 & $14,8 \quad 1,39$ & 9,39 & 13,3 & 15,2 & $14,0 \quad 0,87$ & 6,17 \\
\hline and1 & 16,8 & 19,8 & $18,90,78$ & 4,16 & $17,121,9$ & 19,8 & 1,07 & 5,36 & 17,8 & 20,3 & $18,70,92$ & 4,92 & 17,2 & 18,7 & $3,00,62$ & 3,44 \\
\hline and2 & 19,1 & 22,5 & $21,0 \quad 0,97$ & 4,66 & $21,125,7$ & 22,6 & 3 & 5,43 & 20,3 & 22,8 & $21,4 \quad 0,94$ & 4,41 & 20,3 & 21,7 & 20 & 3,01 \\
\hline anp1 & 35,3 & 44,4 & $41,1 \quad 1,89$ & 4,63 & $39,346,5$ & 43,2 & 1,87 & 4,33 & 39,9 & 43,14 & $41,7 \quad 1,19$ & 2,86 & 40,6 & 42,9 & $41,90,9$ & 2,22 \\
\hline anp2 & 16,2 & 20,6 & $18,41,03$ & 5,62 & $16.521,8$ & 18,9 & 1,49 & 7,90 & 18,0 & 19,9 & $19,10,70$ & 3,66 & 18,5 & 19,7 & $19,00,54$ & 2,85 \\
\hline \multicolumn{17}{|c|}{ Percentagens do comprimento da cabeça } \\
\hline foc & 29,5 & 37,0 & $32,31,94$ & 5,99 & $30,536,2$ & 33,3 & 1,23 & 3,69 & 31,1 & 34,73 & $32,71,21$ & 3,71 & 32,1 & 33,3 & $32,90,56$ & 1,70 \\
\hline olho & 18,9 & 25 & $21,61,80$ & 8,34 & $17,322,1$ & 20,1 & 1,68 & 8,05 & 22,2 & 25,82 & $24,41,46$ & 6,00 & 21,2 & 25,0 & $23,71,79$ & 7,52 \\
\hline interorb & 28,2 & 38,6 & $33,42,68$ & 7,92 & $30,637,8$ & 34,7 & 1,70 & 3,97 & 28,9 & 36,13 & $31,02,64$ & 8,52 & 32,9 & 33,3 & $33,20,22$ & 0,68 \\
\hline boca & 20,2 & 27,1 & $24,0 \quad 1,93$ & 8,07 & $21,629,1$ & 26,1 & 1,64 & 6,29 & 22,6 & 28,62 & $25,9 \quad 1,92$ & 7,42 & 24,2 & 28,2 & $26,3 \quad 1,64$ & 6,26 \\
\hline $\max$ & 28,8 & 35,2 & $31,3 \quad 1,24$ & 3,95 & $28,632,7$ & 31,1 & 1,16 & 3,73 & 31,7 & 32,33 & $32,0 \quad 0,25$ & 0,77 & 32,1 & 32,5 & $32,20,19$ & 0,58 \\
\hline \multicolumn{17}{|l|}{ Contagens } \\
\hline d1 & 4,0 & 7,0 & $5,60,73$ & 13,10 & $4,0 \quad 6,0$ & 4,6 & 0,62 & 13,6 & 4,0 & 5,0 & $4,6 \quad 0,49$ & 10,7 & 4,0 & 5,0 & $4,3 \quad 0,47$ & 10,9 \\
\hline d2 & 8,0 & 10,0 & $8,10,52$ & 6,33 & $8,010,0$ & 8,7 & 0,70 & 8,03 & 9,0 & 9,0 & $9,0 \quad 0,0$ & 0,0 & 9,0 & 9,0 & $9,0 \quad 0,0$ & 0,0 \\
\hline an & 16,0 & 18,0 & 170,53 & 3,14 & $17,019,0$ & 18,2 & 0,77 & 4,24 & 17,0 & 19,0 & $18,40,80$ & 4,35 & 17,0 & 18,0 & $17,70,47$ & 2,67 \\
\hline and2 & 9,0 & 12,0 & $10,10,83$ & 8,21 & $8,011,0$ & 9,9 & 1,19 & 12,0 & 10,0 & 11,0 & $10,6 \quad 0,49$ & 4,62 & 9,0 & 11,0 & $10,3 \quad 0,94$ & 9,12 \\
\hline p1 & 13,0 & 14,0 & $13,90,26$ & 1,85 & $13,0 \quad 15,0$ & 13,9 & 0,59 & 4,26 & 14,0 & 15,0 & $14,6 \quad 0,49$ & 3,36 & 14,0 & 16,0 & $14,7 \quad 0,94$ & 6,43 \\
\hline eslong & 50,0 & 53,0 & $51,60,97$ & 1,88 & $48,053,0$ & 50,6 & 1,59 & 3,13 & 49,0 & 51,0 & $50,4 \quad 0,80$ & 1,59 & 50,0 & 52,0 & $50,70,94$ & 1,86 \\
\hline espd1 & 21,0 & 26,0 & $23,8 \quad 1,37$ & 5,77 & $22,026,0$ & 23,6 & 1,18 & 5,0 & 22,0 & 25,02 & $23,8 \quad 1,17$ & 4,90 & 23,0 & 25,0 & $23,70,94$ & 3,98 \\
\hline esped & 14,0 & 16,0 & $15,60,82$ & 5,27 & $14,0 \quad 16,0$ & 15,9 & 0,52 & 3,25 & 16,0 & 16,0 & $16,0 \quad 0,0$ & 0,0 & 16,0 & 16,0 & $16,0 \quad 0,0$ & 0,0 \\
\hline bras & 6,0 & 8,0 & $7,00,65$ & 9,35 & $6,0 \quad 8,0$ & 7,0 & 0,65 & 9,35 & 8,0 & 9,0 & $8,80,40$ & 4.55 & 7,0 & 9,0 & $8,30.94$ & 11,3 \\
\hline brqi & 20,0 & 24,0 & $22,7 \quad 1,10$ & 4,83 & $20,024,0$ & 22,9 & 1,12 & 4,92 & 22,0 & 24,02 & $23,20,98$ & 4,22 & 23,0 & 24,0 & $23,30,47$ & 2,02 \\
\hline brat & 27,0 & 31,0 & $29,7 \quad 1,28$ & 4,30 & $27,032,0$ & 29,9 & 1,25 & 4,17 & 30,0 & 33,03 & $32,0 \quad 1,26$ & 3,95 & 31,0 & 32,0 & $31,70,47$ & 1,49 \\
\hline
\end{tabular}

Diagnose. Odontesthes argentinensis distingue-se das outras espécies capturadas no Sul do Brasil, pela presença de 27 a 33 rastros no primeiro arco branquial; sobrepõe-se com $O$. aff. perugiae (30 a 37) e $O$. mirinensis (31 a 37), das quais se separa pelo focinho bem menor6,5 a 7,5\% do comprimento padrão, versus 8,0 a $10,7 \%$ 
em O. aff. perugiae; endopterigóides com dentes; ramificação ventral do preopérculo com três orifícios para o canal sensorial, enquanto $O$. mirinensis tem quatro orifícios e em $O$. aff. perugiae o canal está aberto; 48 a 53 escamas na linha longitudinal.

Descrição. O comprimento padrão dos exemplares examinados variou de 105 a $310 \mathrm{~mm}$. As relações morfométricas e merísticas, encontram-se na tabela I. Corpo alongado, recoberto por escamas grandes, ciclóides com bordo posterior irregular, pré-dorsal com escamas crenuladas; cleitrum com escamas no bordo; três a quatro séries de escamas sub-oculares, ausentes no focinho. Cabeça 20 a 22,9\% do comprimento padrão (cp), altura da cabeça 10,3 a 15,4\% do cp, focinho 29,5 a $37,2 \%$ do comprimento da cabeça (cab), olhos grandes 17,3 a $25,8 \%$ da cab, distância inter-orbital 28,1 a $38,6 \%$ da cab; boca protrátil 20,2 a $29,1 \%$ da cab; maxila e mandíbula com mesma projeção anterior; dentes mandibulares pequenos e fortes, agrupam-se em duas fileiras (às vezes três), com distribuição irregular; dentes no vômer pouco visíveis; endopterigóides com uma grande placa de dentes. Origem da primeira dorsal em cima do ânus ou posterior a ele; origem da segunda dorsal na vertical que passa entre o $9^{\circ} \mathrm{e} 11^{\circ}$ raio da anal, terminando ambas na mesma linha vertical. Extremidade distal das nadadeiras peitorais apoiadas à superfície do corpo, alcançam a origem das nadadeiras pélvicas; origem das pélvicas está distante da origem da anal, entre 8 e 12 séries de escamas. Pélvicas muito juntas; a maioria dos exemplares com membrana inter-pélvica unido-as na base ou até a metade, outros ainda, até a extremidade distal dos raios. Dorsal IV a VII e 8 a 10 raios; anal 16 a 19 raios; linha longitudinal com 48 a 53 séries de escamas, das quais 21 a 26 estão localizadas anteriormente à primeira dorsal. Rastros do primeiro arco branquial finos e compridos; 6 a 9 no ramo superior, 20 a 24 no inferior, totalizando 27 a 33 (Fig. 3B). Vértebras pré-caudais 23 a 25, caudais 23 a 24, totalizando 46 a 48; as primeiras vértebras caudais, ao formar o espinho hemal, mantém o arco hemal expandido, por onde se prolonga a bexiga natatória. As paredes dos arcos hemais são alargadas, constituídas de ossos finos que ao se soldarem deixam numerosos orifícios nas laterais do funil hemal. O espinho hemal das três primeiras vértebras é bastante longo.

Observação. Em O. argentinensis, a base das nadadeiras pélvicas está muito próxima, sendo unidas ou não, por uma membrana inter-pélvica. Na maioria dos exemplares analisados, esta membrana une as nadadeiras somente até a metade de seu comprimento, ou está ausente. Portanto não foi possível estabelecer nenhuma relação em função da união das nadadeiras pela membrana inter-pélvica, como pretendia MIRANDA RIBEIRO (1915) ao descrever o gênero Kronia. O autor considerou "as ventrais ligadas entre si", sendo seguido por DE BUEN (1953), que ao recuperar o status genérico de Kronia, descreveu novas espécies, com base na união das nadadeiras pélvicas.

Distribuição geográfica. Odontesthes argentinensis ocorre desde Santos, São Paulo, Brasil ( $24^{\circ} \mathrm{S}$ ), até Mar del Plata e Necochea na Argentina (LAHILlE 1929). Na maior parte dos registros de ocorrência da espécie, é citada sua preferência por ambientes estuarinos. Neste trabalho foram revisados exemplares desde a Lagoa da Conceição, Florianópolis, Santa Catarina, Brasil (276'S), até Quequén, Argentina $\left(38^{\circ} \mathrm{S}\right)$ (Fig. 1). 
Variação intra-específica. A análise dos componentes principais foi realizada com 26 exemplares coletados na Praia do Cassino e 25 do estuário da Lagoa dos Patos (Rio Grande, Rio Grande do Sul), 5 do estuário do rio Tramandai (Tramandai, Rio Grande do Sul) e 3 indivíduos da barra da Lagoa da Conceição. O primeiro componente principal (cpl), explicou 94,9\% da variação total com coeficientes positivos e de semelhante magnitude (Tab. II). Os coeficientes alométricos multivariados, indicaram que os caracteres olho $(\alpha=0,55)$ e maxila $(\alpha=0,86)$, juntamente com cabeça, boca, focinho, distância pré-peitoral (ppl) e distância entre dorsais (dld2), tem alometria negativa, crescendo mais lentamente que o restante do corpo. E, distâncias entre nadadeiras (anpl, anp2, and 1, amd2, pl p2, pl pc) altura da cabeça e a distância pré-anal, tem alometrias positivas, crescendo mais rapidamente que 0 restante do corpo.

Tabela II. Análise dos componentes principais para O. argentinensis (33 exemplares do estuário, 26 da Praia Cassino); matriz de variância-covariância combinada dentro dos grupos para 25 caracteres morfométricos transformados em logaritmos; (cp 1) primeiro eixo extraído dos dados nāo ajustados; $(\alpha)$ coeficiente alométrico; coeficientes CP1 e CP2, obtidos com dados ajustados por projeçōes ortogonais; vide texto para demais abreviaturas.

\begin{tabular}{lcccc}
\hline \multicolumn{1}{c}{ Variáveis } & $c p 1$ & $\alpha$ & $c P 1$ & $C P 2$ \\
\hline $\mathrm{cp}$ & 0,210 & 1,03 & $-0,141$ & 0,051 \\
$\mathrm{pd2}$ & 0,202 & 1,02 & $-0,010$ & 0,110 \\
$\mathrm{pc1}$ & 0,208 & 1,05 & $-0,021$ & 0,051 \\
$\mathrm{pan}$ & 0,211 & 1,06 & $-0,006$ & 0,122 \\
$\mathrm{pp2}$ & 0,203 & 1,02 & 0,008 & 0,216 \\
$\mathrm{pp1}$ & 0,193 & 0,94 & $-0,241$ & 0,064 \\
cab & 0,183 & 0,91 & $-0,120$ & $-0,002$ \\
altcab & 0,197 & 1,08 & 0,595 & $-0,229$ \\
foc & 0,192 & 0,97 & 0,034 & $-0,127$ \\
olho & 0,109 & 0,51 & $-0,271$ & 0,007 \\
interorb & 0,211 & 1,06 & 0,064 & $-0,262$ \\
boca & 0,180 & 0,95 & 0,228 & $-0,311$ \\
max & 0,172 & 0,85 & $-0,149$ & $-0,213$ \\
altped & 0,198 & 1,00 & 0,079 & $-0,310$ \\
p1p2 & 0,217 & 1,12 & 0,174 & 0,319 \\
p1pc & 0,219 & 1,09 & $-0,087$ & 0,098 \\
p2pc & 0,205 & 1,02 & $-0,066$ & 0,146 \\
anpc & 0,201 & $-0,228$ & $-0,074$ \\
d1pc & 0,98 & $-0,259$ & $-0,128$ \\
d2pc & 0,208 & $-0,394$ & $-0,320$ \\
d1d2 & 0,216 & 0,020 & 0,226 \\
and1 & 0,187 & 0,141 & $-0,042$ \\
and2 & 0,215 & 0,96 & 0,152 \\
anp1 & 0,203 & 1,10 & 0,193 & 0,330 \\
anp2 & 0,220 & 1,05 & 0,125 & 12,317 \\
\hline Variância (\%) & 0,211 & 1,12 & 0,070 & 100 \\
\hline
\end{tabular}

No conjunto de dados ajustados pelas projeções ortogonais, os dois primeiros eixos representaram 29,8\% e 12,1\%, respectivamente, da variância total, com coeficientes positivos e negativos, indicando aspectos da forma do corpo. O diagrama de dispersão dos pontos indicou a formação de dois grupos. Um dos grupos reuniu os peixes de Tramandai e Conceição com os do estuário da Lagoa dos Patos, 
indicando afinidade entre os grupos estuarinos. O outro grupo foi formado pelos morfotipos da Praia do Cassino (Fig. 4). Esta variabilidade morfológica foi interpretada como diferenciação geográfica, sugerindo que crescimento e desenvolvimento da espécie, ocorram sob diferentes regimes ambientais (BEMVENUTI 2000). Este padrão de diferenciação representa o contraste entre duas séries de variáveis no primeiro componente principal, indicando aspectos da forma do corpo. As variáveis de coeficientes negativos, d2pc, olho, $\mathrm{d}$ lpc, ppl, anpc, relacionaram-se com medidas oblíquas, longitudinais ao comprimento do peixe, tendo influenciado a distribuição dos exemplares da Praia do Cassino, cujas proporções corporais apresentaram menores médias. E, as variáveis de coeficientes positivos, altcab, boca, and2, plp2, andl, relacionaram-se com medidas verticais influenciando os grupos estuarinos com maiores médias nas proporções corporais (Tabs I e II).

\section{Odontesthes bonariensis (Valenciennes, 1835)}

Fig. 5A, Tab. III

Atherina bonariensis Valenciennes, 1835: 348 In: Cuvier \& Valenciennes (localidade-tipo: Bucnos Aires, Argentina).

Odontesthes bonariensis; Ringuelet, 1942: 429.

Material examinado. Espécimens tipo: Holótipo de Atherina bonariensis MNHM A.4407 (216 mm cp); parátipos MNHM A. 4406 (216 mm, 223 mm, 238 $\mathrm{mm} \mathrm{cp}$ ) Rio de la Plata, Argentina (somente dados biométricos).

Outros espécimens examinados. BRASIL, Rio Grande doSul: FURG 86.0015 (1) Lagoa Mangueira, ago 1986; FURG 86.0016 (3) idem, ago 1986; FURG 86.0019 (11) Lagoa dos Quadros, Osório, set 1986; FURG 86.0021 (4) Lagoa Mirim, 22 set 1986; FURG 86.0022 (4) SãoLourenço do Sul, Lagoa dos Patos, 22 set 1986; FURG 86.0039 (1) Lagoa Mirim, 28 jul 1986; FURG 87.0018 (2) Lagoa Mangueira, jul 1987; FURG 87.0027 (3) Lagoa Mirim, 27 out 1987; FURG 87.0031 (2) idem, 26 jun 1987; FURG 87.0035 (2) Lagoa Mangueira, jul 1987; FURG 87.0041 (2) Lagoa Mirim, 20 out 1987; FURG 87.0054 (1) Lagoa Mangueira, jul 1987; FURG 87.0055 (1) Lagoa Mirim, jul 1987; FURG 87.0057 (1) Lagoa Mirim, 31 jul 1987; FURG.87.0058 (2) Saco de Itapoã, Lagoa dos Patos, 25 jul 1987; FURG 87.0059 (1) Lagoa Mangueira, jul 1987; FURG 87.0060 (2) Arroio del Rei, Lagoa Mirim, 18 jul 1987; FURG 88.0003 (1) Lagoa Mirim, 22 jul 1988; FURG 88.0004 (1) Lagoa dos Patos 2 jun 1988; MCP 0651 (1) Ponta de Itapoã, 2 mar 1981; MCP 7521 (1) Tramandaí, mar 1973; MCP 7544 (1) idem; MCP 8221 (1) sul da Lagoa Mangueira; MCP 8367 (1) Lomba do Sabão, 22 dez 1975; MCP 8368 idem; MCP 8528 (1) Barragem do Capané, Cachoeira do Sul; MCP 8530 (1) idem; MCP 8543 (1) Farroupilha, 10 mar 1978. URUGUAI: INAPE s/n. (3) Laguna del Diário, Maldonado dez 1991. ARgENTINA: MLP 1.3.41.25 (1) Rio Uruguai, Entre Rios 1 mar 1941.

Diagnose. Odontesthes bonariensis distingue-se das outras espécies capturadas no sul do Brasil pela cabeça afilada, côncava dorsalmente; focinho pontudo (7,9 a 10,4\% do comprimento padrão), semelhante a $O$. aff. perugiae (8,0 a 10,7\% do $\mathrm{cp}$ ) do qual difere pelo maior número de rastros no primeiro arco branquial, 40 a 47 contra 28 a 37 em $O$. aff. perugiae; 50 a 59 escamas na linha longitudinal. 


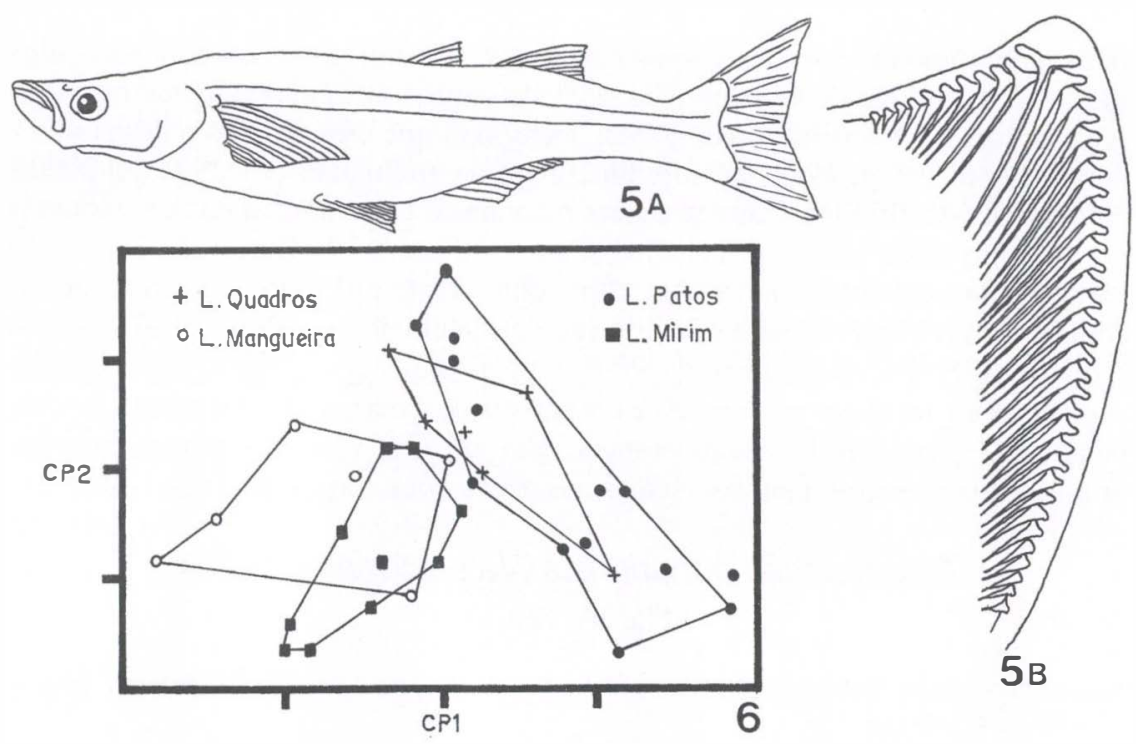

Figs 5-6. Odontesthes bonariensis. (5) Exemplar de $260 \mathrm{~mm}$ de comprimento padrāo (A) FURG 86.0019 Lagoa dos Quadros, Rio Grande do Sul, setembro de 1986, (B) primeiro arco branquial esquerdo; (6) projeçāo dos escores individuais de 34 exemplares, no espaço dos dois primeiros componentes principais (CP1,CP2), para 25 caracteres morfométricos; dados ajustados com projeçōes ortogonais de Burnaby.

Descrição. O comprimento padrão dos exemplares examinados variou de 110 a $365 \mathrm{~mm}$. As relações morfométricas e merísticas encontram-se na tabela III. Corpo alto, relativamente curto, comprimido lateralmente, recoberto por escamas grandes ciclóides de bordo posterior liso; duas séries de escamas sub-oculares; cleitrum sem escamas no bordo; ventre arredondado. Cabeça grande, ligeiramente côncava no dorso 23,3 a 28,8\% do comprimento padrão (cp). Focinho proeminente 31,7 a $37 \%$ do comprimento da cabeça (cab); boca larga 23,7 a $30,0 \%$ da cab; mandíbula mais comprida que o prémaxilar; maxilar em posição oblíqua, distância entre o término da fenda bucal e o bordo anterior do olho, menor que o diâmetro do olho, este com 12,4 a 16,9\% da cab. Dentes mandibulares pequenos em três a quatro séries; endopterigóides com placas de dentes reduzidos; vômer sem dentes. Origem da primeira dorsal entre o final das pélvicas e o ânus; origem da segunda dorsal na vertical que passa entre o $8^{\circ}$ e $10^{\circ}$ raio da anal, terminando adiante da extremidade distal desta. Extremidade distal das peitorais apoiadas à superfície do corpo, alcança a origem das pélvicas; pélvicas bem separadas. Dorsal IV a VI e 8 a 11 raios, anal 15 a 19 raios, linha longitudinal com 50 a 59 séries de escamas, das quais 21 a 28 estão localizadas anteriormente à primeira dorsal. Rastros do primeiro arco branquial finos, compridos, 8 a 11 na parte superior, 32 a 37 na inferior, totalizando 40 a 47 (Fig. 5B). Vértebras: 27 pré-caudais, 22 a 23 caudais, totalizando 49 a 50; as primeiras 10 vértebras caudais mantém o arco hemal expandido cujas paredes alargadas, formam um funil hemal fechado, por onde se prolonga a bexiga natatória. 
Comentários. Odontesthes bonariensis é uma espécie pouco citada na literatura, pois, além de ter sido denominada por vários autores, como Basilichthys bonariensis, algumas das descrições apresentadas eram baseadas em variedades da espécie bonariensis, consideradas atualmente com diferentes status específico (LAHILlE 1929, DE BUEN 1953).

Tabela III. Dados comparativos dos caracteres morfométricos e merísticos de quatro populaçōes de $O$. bonariensis. Medidas expressas como percentagens do comprimento padrāo e comprimento da cabeça; (cv) coeficiente de variaçāo; vide texto para demais abreviaturas.

\begin{tabular}{|c|c|c|c|c|c|c|c|c|c|c|c|c|c|c|c|c|c|}
\hline \multirow{2}{*}{ Variáveis } & \multicolumn{4}{|c|}{ Lagoa Mangueira $(n=12)$} & \multicolumn{4}{|c|}{ Lagoa Mirim $(n=10)$} & \multicolumn{4}{|c|}{ Lagoa dos Patos $(n=6)$} & \multicolumn{5}{|c|}{ Lagoa dos Quadros $(n=8)$} \\
\hline & Min & Máx $N$ & s & v & Min 1 & $\mathrm{ix}$ & Des & $\mathrm{cv}$ & Min 1 & t & s & v & Min 1 & áx & éd & Des & 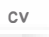 \\
\hline $\mathrm{cp}(\mathrm{mm})$ & 230 & 309 & & & 231 & 347 & & & 265 & 365 & & & 37 & 352 & & & \\
\hline \multicolumn{18}{|c|}{ Percentagem do comprimento padrāo } \\
\hline pd1 & 58,2 & $61,760,2$ & 1,1 & 1,8 & 59,6 & $62,360,5$ & 0,8 & 1,4 & 60,0 & $63,161,5$ & 1,2 & 2,5 & 60,3 & 63,5 & 62,2 & 1,1 & 1,8 \\
\hline pd2 & 1,4 & $75,673,4$ & 1,4 & 1,9 & 72,4 & $77,3 \quad 74,6$ & 1,4 & 1,9 & 72,9 & $76,4 \quad 75,2$ & 1,3 & 2,1 & 73,4 & 77,0 & 75,2 & 1,3 & 1,7 \\
\hline pan & 65,4 & $70,568,1$ & 1,6 & 2,3 & 65,6 & $72,7 \quad 68,7$ & 1,8 & 2,7 & 65,3 & $70,368,5$ & 1,8 & 2,5 & 66,0 & 69,6 & 67,9 & 1,2 & 1.7 \\
\hline pp1 & 25,4 & $27,626,8$ & 0,6 & 2,2 & 26,9 & $29,528,6$ & 0,9 & 3,0 & 28,8 & $30,129,1$ & 0,7 & 2,6 & 26,9 & 28,6 & 27,7 & 0,6 & 2,2 \\
\hline pp2 & 4 & $, 547,9$ & 1,8 & 3,7 & 47,7 & $51,549,8$ & 1,1 & 2,3 & 48,7 & $52,350,7$ & 1,5 & 2,8 & 44,8 &, 4 & 47,6 & .4 & 3,0 \\
\hline$c a b$ & & 3 & 0,7 & 2,8 & 26,1 & & 0,8 & 3,0 & & & 1,0 & .5 & & & 3 & 5 & 1,8 \\
\hline altca & & 6 & 8 & 5,4 & 1 & 7 & 4 & 2,9 & & & 0 & 7 & & & 5 & 0 & 7.5 \\
\hline foc & 9 & $9,0 \quad 8,5$ & 0,4 & 4,4 & 8,5 & $9,5 \quad 9,2$ & 0,2 & 2,7 & 8,7 & $10,4 \quad 9,5$ & 0,6 & 5,9 & & 5 & 9,3 & 8 & 0,3 \\
\hline pe & 6 & $9,5 \quad 8,3$ & 0,5 & 5,7 & 7,5 & $9,0 \quad 8,3$ & 0,5 & 5,8 & 7,1 & $8,4 \quad 7,8$ & 0,5 & 6,1 & 8 & 7 & 8,9 & 3 & 0,4 \\
\hline $1 \mathrm{p} 2$ & & 124,2 & 1.3 & 5,3 & 22,5 & $26,523,7$ & 1,2 & 4,9 & 23,6 & $26,124,5$ & 0,8 & 3,3 & 20,7 & 1 & 23,9 & 7 & .4 \\
\hline$p c$ & & 075,0 & 1,3 & 1,7 & 72,5 & $76,6 \quad 74,5$ & 1,2 & 1,6 & 72,3 & $75,8 \quad 74,1$ & 1,1 & 1,4 & 9 & 76,6 & 74,7 & 1,0 & 3 \\
\hline$p c$ & & 35 & 7 & 3,0 & 7 & 45 &, 3 & 2,4 & & 253,6 & 0,9 & 1,6 & 1 & 6 & 4 & 1,3 & 2,3 \\
\hline$p c$ & & 3 & 6 & 4,5 & 4 & 03 & 0 & 2,8 & & 1 & 6 & 1,9 & 6 & 10 & & 3 & 3,6 \\
\hline 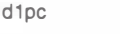 & & 4 & 1,4 & 3,5 & 4 & 3 & 1 & 2,8 & 7 & 0 & 1,5 & 3,5 & 4 & 2 & 3 & 5 & 3,8 \\
\hline d2pc & & 42 & 1.1 & 4,0 & 24,2 & 3 & .1 & 4,2 & 24,4 & $26,825,5$ & 0,7 & 2,7 & 0 & 26,9 & 8 & 1,0 & 3,9 \\
\hline d1d2 & & $5 \quad 13,3$ & 0,8 & 6,2 & 12,8 & $14,6 \quad 13.9$ & 0,6 & 4,4 & 11,5 & $14,8 \quad 13,7$ & 1.1 & 8,2 & 12,2 & 15,8 & 13,7 & 1,1 & 8,3 \\
\hline all & & 920,1 & 1,2 & 6,1 & 18,8 & $20,9 \quad 19,7$ & 0,6 & 2,9 & 17,4 & $19,0 \quad 18,1$ & 0,6 & 3,5 & 18,4 & 20,3 & 19,4 & 0,6 & 3,3 \\
\hline 110 & & 920,9 & 1,0 & 4,8 & 19,5 & $21,520,5$ & 0,7 & 3,4 & 17,8 & $20,519,0$ & 1,0 & 5,4 & 19,9 & .5 & 20,6 & 0.6 & 2,8 \\
\hline al & & 42,8 & 2,1 & 5,0 & 40,4 & $46,7 \quad 42,5$ & 8 & 4,3 & 42,2 & $44,7 \quad 43,0$ & 0,9 & 2,2 & 0,1 & 44,9 & 42,5 & 1,3 & 3,1 \\
\hline aripe & & $23,120,8$ & 1,6 & 7,6 & 18,0 & & & 6,8 & 2 & $21,0 \quad 19,6$ & 1,2 & 6,2 & 1 & & 1.0 & 5 & 7.3 \\
\hline \multicolumn{18}{|c|}{ Percentagem do comprimento da cabeça } \\
\hline foc & & & 1,0 & 3,0 & & $35,333,5$ & & 3,3 & & & 1,6 & 4,7 & & & & 1,2 & 3.7 \\
\hline he & & 9 15 & 1.3 & 8,4 & 5 & $15,714,2$ & 1,1 & 7,6 & 12,4 & 31 & 1,1 & 7,8 & 5 & 1 & 6 & 0,7 & 4,3 \\
\hline & 2 & 627,8 & 1,7 & 6,0 & 25,7 & $29,727,4$ & 1,4 & 5,1 & 25,0 & $28,426,8$ & 1,2 & 4,6 & 24,6 & 26,6 & 25,7 & 0,7 & 2,8 \\
\hline boca & 2 & $27,826,0$ & 1,3 & 5,0 & 25,9 & $30,027,6$ & 1,1 & 4,1 & 25,3 & $29,327,7$ & 1,4 & 4,8 & 23,9 & 28,4 & 25,5 & 1,5 & 5,7 \\
\hline $\max$ & 32,4 & $35,8 \quad 34,2$ & 0,9 & 2,6 & 32,9 & $37,134,7$ & 1,1 & 3,2 & 33,3 & $37,135,8$ & 1,4 & 3,9 & 33,6 & 35,9 & 35,0 & 0,7 & 2,0 \\
\hline \multicolumn{18}{|l|}{ Cont } \\
\hline d1 & 4.0 & $6,0 \quad 4,8$ & 0,7 & 8 & 4,0 & $6,0 \quad 4,9$ & 0,6 & 0 & 4,0 & $6,0 \quad 4,7$ & 0,8 & 17,0 & 0 & . & 4,7 &, 5 & 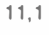 \\
\hline d2 & & $\begin{array}{ll}0 & 9,8\end{array}$ & 0,8 & 7 & 0 & $11,0 \quad 9,9$ & 6 & 0,1 & 0 & 11,01 & 6 & & 0 & 10 & 0 & 9 & 10 \\
\hline an & 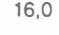 & 0,0 & 1 & 5,8 & 0 & $17,0 \quad 16,2$ & 6 & 3,9 & 0 & 01 & 0 & 8 & 0 & 0 & 7 & 4 & 0,2 \\
\hline and: & & $10,0 \quad 8$, & 0,9 & 10,6 & 8,0 & $9,0 \quad 8,4$ & 0,5 & 6,1 & 8,0 & $10,0 \quad 9,0$ & 0,6 & 7,0 & 8,0 & 10,0 & 9,2 & 0,8 & 0 \\
\hline & 13,0 & $14,0 \quad 13,9$ & 0,3 & 2,1 & 12,0 & $13,0 \quad 12,4$ & 0,5 & 4,2 & 13,0 & $14,0 \quad 13,2$ & 0,4 & 3,1 & 12,0 & 15,0 & 13,2 & 1,6 & 12. \\
\hline esic & 50.0 & $59,0 \quad 54,7$ & 2,7 & 5,0 & 51,0 & $54,0 \quad 52,4$ & 0,8 & 1.6 & 51,0 & $55,0 \quad 53,0$ & 1,4 & 2,7 & 55,0 & 59,0 & 57,7 & 5 & \\
\hline espd1 & 4.0 & $28,025,6$ & 1,4 & 5.6 & 21,0 & $23,022,2$ & 0,6 & 2,8 & 21,0 & $25,022.7$ & 1.6 & 7.2 & 23.0 & 28,0 & 26.0 & 9 & 7.3 \\
\hline esped & 16,0 & $20,017,0$ & 1,3 & 7,9 & 16,0 & $18,0 \quad 17,0$ & 1,1 & 6,2 & 16,0 & $18,0 \quad 17,3$ & 1,0 & 6,0 & 16,0 & 18,0 & 16,5 &, 0 & 6,1 \\
\hline brqs & 8,0 & $10,0 \quad 9,0$ & 0,8 & 8,6 & 9.0 & $11,0 \quad 9,6$ & 0.7 & 7,3 & 9,0 & $10,0 \quad 9.8$ & 0,4 & 4,2 & 10,0 & 11,0 & 10.7 & 0,5 & .8 \\
\hline brai & 32,0 & $37,033,1$ & 1,6 & 4,8 & 32,0 & $34,0 \quad 32,7$ & 0,8 & 2,5 & 32,0 & $36,0 \quad 34,2$ & 1,6 & 4,7 & 33,0 & 36,0 & 34,2 & 1,3 & 0.0 \\
\hline brat & 40,0 & $47,0 \quad 42,1$ & 2,1 & 4,9 & 41,0 & $44,0 \quad 42,3$ & 0,9 & 2,2 & 42,0 & $46,0 \quad 44,3$ & 1,6 & 3,7 & 43,0 & 47,0 & 44,8 & 1,7 & 3,8 \\
\hline
\end{tabular}


Distribuição geográfica. Odontesthes bonariensis é uma espécie originária da Argentina. Foi encontrada no Rio da Prata, Rio Uruguai, Rio Paraná e lagoas da Argentina (LAHILLE 1929) tendo sido introduzida em várias lagoas da América do Sul. KLEEREKOPER (1945) e GODOI (1946) desenvolveram estudos de aterinocultura na Lagoa dos Quadros, ao norte do Rio Grande do Sul. No presente trabalho foram revisados exemplares das lagoas dos Quadros, Itapeva, Mirim, Mangueira, dos Patos e af luentes do Rio Guaíba, Porto Alegre, Rio Grande do Sul. Também foram medidos exemplares da Província de Rocha, Uruguai (Fig. 1) e Entre Rios, Argentina.

Variação Intra-específica. A análise dos componentes principais foi realizada com 32 exemplares, sendo 11 da Lagoa Mangueira, 9 da L. Mirim, 6 da L. dos Quadros e 6 da L. dos Patos. O primeirocomponente principal (cpl), explicou 88,0\% da variação total com coeficientes positivos e de semelhante magnitude (Tab. IV). Os coeficientes alométricos multivariados, indicaram que os caracteres olho ( $\alpha=$ $0,66)$ e dld $2(\alpha=0,76)$, juntamente com a distância entre nadadeiras (anp2, andl, and2), a distância entre nadadeiras e o pedúnculo caudal (d2pc, d2pc, anpc, p2pc, plpc) e altura do pedúnculo, tem alometria negativa, crescendo mais lentamente que o restante do corpo. E, altura da cabeça, cabeça, focinho, boca, distância pré-anal, pré-peitoral ( $\mathrm{ppl}$ ) e distância entre nadadeiras ( $\mathrm{plp2}$ ), tem alometrias positivas, crescendo mais rapidamente que o restante do corpo (Tab. IV).

Tabela IV. Análise dos componentes principais para O. bonariensis ( 17 exemplares da Lagoa Quadros e Mangueira, 15 Lagoa Mirim e Patos); matriz de variância-covariância total para 25 caracteres morfométricos transformados em logaritmos; (cp1) primeiro eixo extraído dos dados não ajustados; $(\alpha)$ coeficiente alométrico; coeficientes CP1 e CP2 obtidos com dados ajustados por projeçōes ortogonais.

\begin{tabular}{|c|c|c|c|c|}
\hline Variáveis & $c p 1$ & $\alpha$ & $\mathrm{CP} 1$ & CP2 \\
\hline$c p$ & 0,201 & 1,01 & 0,092 & 0,041 \\
\hline pd2 & 0,204 & 1,03 & 0,023 & 0,057 \\
\hline pc1 & 0,204 & 1,03 & 0,024 & 0,113 \\
\hline pan & 0,216 & 1,09 & 0,025 & 0,111 \\
\hline pp2 & 0,226 & 1,14 & $-0,122$ & 0,063 \\
\hline pp1 & 0,212 & 1,07 & $-0,170$ & $-0,099$ \\
\hline$c a b$ & 0,227 & 1,15 & $-0,190$ & $-0,062$ \\
\hline altcab & 0,213 & 1,07 & $-0,176$ & 0,085 \\
\hline foc & 0,223 & 1,13 & $-0,275$ & $-0,117$ \\
\hline olho & 0,131 & 0,66 & $-0,059$ & $-0,063$ \\
\hline interorb & 0,212 & 1,07 & $-0,084$ & $-0,348$ \\
\hline boca & 0,250 & 1,26 & $-0,433$ & $-0,089$ \\
\hline $\max$ & 0,234 & 1,18 & $-0,303$ & $-0,084$ \\
\hline altped & 0,162 & 0,82 & 0,227 & $-0,121$ \\
\hline p1p2 & 0,229 & 1.16 & 0,086 & 0,129 \\
\hline p1pc & 0,193 & 0,97 & 0.144 & 0,026 \\
\hline p2pc & 0,180 & 0,91 & 0,206 & 0,091 \\
\hline anpc & 0,185 & 0,93 & 0,226 & $-0,191$ \\
\hline d1pc & 0,182 & 0,92 & 0,137 & $-0,206$ \\
\hline d2pc & 0,170 & 0,86 & 0,221 & $-0,206$ \\
\hline d1d2 & 0,150 & 0,76 & $-0,005$ & 0,063 \\
\hline and1 & 0,181 & 0,91 & 0,347 & $-0,076$ \\
\hline and2 & 0,176 & 0,89 & 0,382 & $-0,176$ \\
\hline anp1 & 0,210 & 1,06 & 0,046 & 0,338 \\
\hline anp2 & 0,281 & 0.93 & 0.063 & 0,689 \\
\hline Variância (\%) & 88,000 & & 29,300 & 17,300 \\
\hline
\end{tabular}

Revta bras. Zool. 19 (1): $251-287,2002$ 
No conjunto de dados ajustados pelas projeções ortogonais, os dois primeiros eixos representaram $29,3 \%$ e 17,3\%, respectivamente da variância total, com coeficientes positivos e negativos, indicando aspectos da forma do corpo. No diagrama de dispersão dos pontos, observa-se a formação de dois grupos de acordo com a área onde foram amostrados (Fig. 6). Um dos grupos reuniu os indivíduos coletados na Lagoa dos Quadros e Lagoa Mangueira, ambas lagoas fechadas, no outro, os peixes coletados na Lagoa Mirim estiveram mais relacionados com os da Lagoa dos Patos, devido à ligação entre estas lagoas, através do Canal São Gonçalo (Fig. 1). Este padrão de diferenciação representa o contraste entre duas séries de variáveis. Aquelas com coeficientes positivos (and2, and1, altped, anpc), relacionaram-se com a região caudal, tendo proporcionalmente maiores médias nos indivíduos da Lagoa Mangucira. As variáveis com coeficientes negativos (boca, max, foc, cab), relacionaram-sc com a região da cabeça, resultando em menores proporções corporais médias dos peixes da Lagoa Mangueira (Tabs. III e IV).

\section{Odontesthes humensis De Buen, 1953}

Fig. 7A, Tab. V

Odontesthes humensis De Buen, 1953: 34 (localidade-tipo: Rio Negro, Uruguai).

Odontesthes gucuzu De Buen, 1953: 40 (localidade-tipo: Rio Uruguai, Uruguai); Syn. n.

Material examinado. Espécimens tipo: Holótipo de Odontesthes humensis: MHNM 1806 (137 mm cp), parátipos (10) MHNM 1807 (110 -161 mm cp) Rio Negro, Bacia do Rio Uruguay, Uruguay; holótipo de Odontesthes guazu: MHNM 1805 (112 mm cp) Rio Uruguay, Salto, Bacia do Rio Uruguay, Uruguay.

Outros espécimens examinados. BRASIL, Rio Grande do Sul: FURG 86.0001 (3) Lagoa Mangueira, ago 1986; FURG 86.0002 (3) Lagoa Mirim, 29 jul 1986; FURG 86.0003 (3) Lagoa Mangueira, ago 1986; FURG 86.0023 (3) São Lourenço, Lagoa dos Patos, 22 set 1986; FURG 87.0001 (2) Lagoa Mirim, Taím 31 jul 1987; FURG 87.0002 (12) idem, 18 jul 1987; FURG 87.0003 (2) Lagoa Mangueira, jul 1987; FURG 87.0004 (2) Lagoa Mirim, jul 1987; FURG 87.0028 (12) Lagoa Mirim, Taím 27 out 1987; FURG 87.0066 (1) Lagoa Mangueira jul 1987; FURG 87.0067 (1) idem, jul 1987; FURG 87.069 (1) ibidem, jul 1987; FURG 87.0068 Lagoa Mirim, 20 out 1987; FURG 87.0070 Arroio del Rei, Lagoa Mirim, 18 jul 1987; FURG 88.0010 (7) Lagoa Mirim, 22 set 1988; FURG 92.0006(2)Lagoa Mangueira, ago 1992; MCN 5707 (1) Arroio do Conde, Rio Jacuí (sem data); MCP 6870 (1) Rio Guaíba, 27 dez 1984; MCP 6893 (2) idem, 29 jan 1985; MCP 7940 (1) Açude dos Garcia, Barra do Ribeiro (sem data); MCP 10600 (3) Ilha do Junco, Porto Alegre 28 nov 1985. UruguaI: FURG 91.006 (1) Embalse del Rio Negro, Rincón del Bonetti 17 dez 1991.

Diagnose. Odontesthes humensis distingue-se das outras espécies que habitam o sul do Brasil, por possuir pequeno número de rastros no primeiro arco branquial (20 a 24 contra mais de 27 nas demais espécies); olhos em posição inferior; distância inter-orbital (31,3 a 38,6\% do comprimento da cabeça) mais larga que nas demais espécics. 

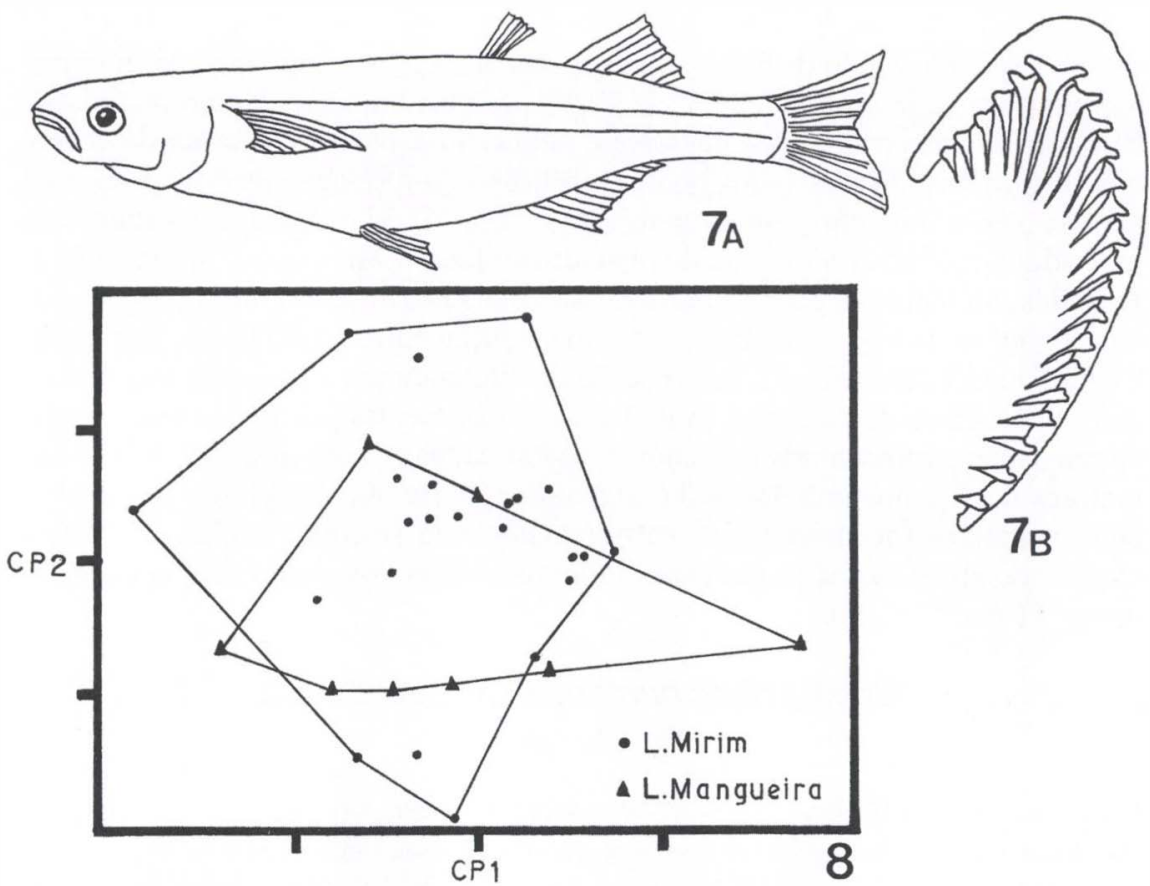

$7 \mathrm{~B}$

Figs 7-8. Odontesthes humensis. (7) Exemplar de $200 \mathrm{~mm}$ de comprimento padrāo (A) FURG 87.0002 Lagoa Mirim, Rio Grande do Sul, 18 de julho de 1987; (B) primeiro arco branquial esquerdo; (8) projeçāo dos escores individuais de 32 exemplares, no espaço dos dois primeiros componentes principais (CP1, CP2), para 25 caracteres morfométricos; dados ajustados com projeçōes ortogonais de Burnaby.

Descrição. O comprimento padrão dos exemplares examinados variou de 180 a $305 \mathrm{~mm}$. As relações morfométricas e merísticas encontram-se na tabela V. Corpo alargado lateralmente, ventre arredondado, escamas do corpo de bordo posterior liso; duas séries de escamas sub-oculares, ausentes no focinho; cleitrum sem escamas no bordo. Cabeça arredondada 23,3 a 25,4\% do comprimento padrão (cp); altura 12 a $16,5 \%$ do cp. Focinho curto 31,3 a 35,6\% do comprimento da cabeça (cab); olhos pequenos, posição inferior 15,8 a $21 \%$ da cab; distância inter-orbital grande 31,3 a $38,6 \%$ da cab. Boca protrátil com largura entre 23,5 e 30,2\% da cab, maxila curva, dirigida para baixo, mais saliente que a mandíbula, com duas fileiras de pequenos dentes. Extremidade do maxilar atinge o bordo anterior do olho; dentes ausentes no vômer e no endopterigóide. Origem da primeira dorsal entre o final das pélvicas e o ânus; segunda dorsal origina-se na altura do $8^{\circ}$ a $9^{\circ}$ raio da nadadeira anal, terminando as duas na mesma vertical. Extremidade distal das nadadeiras peitorais, apoiadas à superfície do corpo, não alcança a origem das pélvicas, faltando uma escama e meia; pélvicas totalmente separadas entre si. Dorsal III a VI e 8 a 11 raios; anal 16 a 18 raios; linha longitudinal com 50 a 57 séries de escamas, das quais 22 a 26 estão localizadas anteriormente à primeira dorsal. Rastros do primeiro arco branquial curtos, grossos, 
Tabeia V. Dados comparativos dos caracteres morfométricos e merísticos de duas populaçōes de $O$. humensis. Medidas expressas em percentagens do comprimento padrāo e comprimento da cabeça; (cv) coeficiente de variação.

\begin{tabular}{|c|c|c|c|c|c|c|c|c|c|c|}
\hline \multirow{2}{*}{ Variáveis } & \multicolumn{5}{|c|}{ Lagoa Mirim ( $n=23$ ) } & \multicolumn{5}{|c|}{ Estuário Mangueira $(n=9)$} \\
\hline & Min & Máx & Méd & Des & CV & Min & Máx & Méd & Des & cv \\
\hline $\mathrm{cp}(\mathrm{mm})$ & 180 & 305 & & & & 240 & 270 & & & \\
\hline \multicolumn{11}{|c|}{ Percentagem do comprimento padrāo } \\
\hline pd1 & 56,6 & 61.9 & 59.4 & 1.46 & 2,47 & 56.0 & 59,8 & 58,0 & 1.10 & 1,89 \\
\hline pd2 & 70,6 & 75,8 & 73,4 & 1,37 & 1,86 & 70,8 & 75,0 & 73,0 & 1,41 & 1,94 \\
\hline pan & 61,1 & 68.7 & 65,2 & 1,92 & 2,95 & 62,9 & 67.1 & 65,2 & 1,33 & 2,04 \\
\hline pp1 & 25,6 & 28,0 & 26,7 & 0,58 & 2,16 & 24,7 & 26,3 & 25,5 & 0,49 & 1,93 \\
\hline pp2 & 42,7 & 50,6 & 46,0 & 2,18 & 4,74 & 44,6 & 47.9 & 45,8 & 1,13 & 2,46 \\
\hline cab & 23,5 & 25,4 & 24,5 & 0,60 & 2,43 & 23,3 & 24,5 & 23,6 & 0,44 & 1,87 \\
\hline altcab & 12,4 & 16,2 & 14.4 & 1.05 & 7,31 & 12,0 & 16,5 & 15,0 & 1.40 & 9,35 \\
\hline foc & 7.5 & 8,9 & 8,1 & 0,35 & 4,32 & 7,6 & 8,6 & 8,0 & 0,29 & 3,61 \\
\hline altped & 7.5 & 9,0 & 8,3 & 0,38 & 4,59 & 7,4 & 8.7 & 8,2 & 0,39 & 4,74 \\
\hline p1p2 & 20,8 & 25,5 & 23,2 & 1,26 & 5,43 & 22,4 & 24,7 & 23,9 & 0,80 & 3,37 \\
\hline p1pc & 73.1 & 78,3 & 76,1 & 1,41 & 1,85 & 73,7 & 78,8 & 76,3 & 1,67 & 2,19 \\
\hline p2pc & 54,7 & 60,9 & 58,3 & 1,62 & 2,78 & 53,9 & 60,4 & 57.6 & 2,07 & 3,59 \\
\hline anpc & 35,8 & 40,7 & 38,0 & 1,32 & 3,47 & 35,0 & 38,4 & 36.7 & 1,10 & 2,99 \\
\hline dipc & 40,7 & 45,8 & 42.9 & 1,35 & 3,15 & 40,7 & 46,0 & 42,2 & 1,70 & 4,02 \\
\hline d2pc & 25,2 & 31,4 & 28,6 & 1.43 & 5,01 & 25,9 & 31,8 & 28,2 & 1.71 & 6,06 \\
\hline d1d2 & 12,5 & 16,6 & 14,5 & 1,01 & 6,96 & 13,3 & 16,4 & 15,1 & 0,81 & 5,37 \\
\hline and 1 & 18,4 & 21.9 & 20,4 & 0,89 & 4,34 & 18,5 & 21.0 & 20.1 & 0,68 & 3,40 \\
\hline and2 & 18,8 & 23,2 & 21,2 & 1,05 & 4,94 & 19.6 & 21,3 & 20,6 & 0,43 & 2,07 \\
\hline anp1 & 39,4 & 44,8 & 42,3 & 1,64 & 3,88 & 40,3 & 44,1 & 42,2 & 1,34 & 3,18 \\
\hline anp2 & 18,6 & 23,9 & 20,8 & 1,50 & 7,21 & 19,8 & 23,3 & 21,2 & 0,89 & 4,21 \\
\hline \multicolumn{11}{|c|}{ Percentagem do comprimento da cabeça } \\
\hline foc & 31,3 & 35,6 & 33,0 & 1,18 & 3,56 & 32,5 & 35,6 & 33,9 & 1,02 & 3,00 \\
\hline olho & 16,1 & 21,1 & 19,1 & 1,00 & 5,25 & 15,8 & 19,5 & 17.5 & 1,13 & 6,43 \\
\hline interorb & 31,3 & 37,6 & 35,4 & 1,74 & 4,92 & 33,3 & 38,6 & 35,8 & 1,69 & 4,74 \\
\hline boca & 23,5 & 30,2 & 26,8 & 1,86 & 6,96 & 24,6 & 30,0 & 27,7 & 1,64 & 5,91 \\
\hline $\max$ & 29,9 & 36,4 & 33,1 & 1,62 & 4,90 & 32,6 & 35.5 & 33,8 & 0,89 & 2,64 \\
\hline \multicolumn{11}{|l|}{ Contagens } \\
\hline d1 & 3 & 6 & 4.7 & 0,7 & 15.9 & 5 & 5 & 5,0 & 0,0 & 0,0 \\
\hline$d 2$ & 8 & 11 & 9.4 & 0,8 & 8,7 & 9 & 10 & 9,6 & 0,5 & 5,2 \\
\hline an & 16 & 17 & 16,6 & 0,5 & 3,0 & 16 & 18 & 16,7 & 0.7 & 4,0 \\
\hline and2 & 8 & 10 & 8,9 & 0.7 & 8,2 & 8 & 9 & 8.2 & 0,4 & 5,1 \\
\hline p1 & 12 & 14 & 13,3 & 0,6 & 4,7 & 13 & 14 & 13,8 & 0,4 & 3,0 \\
\hline eslong & 50 & 56 & 53,3 & 1,8 & 3,5 & 54 & 57 & 55,1 & 1,0 & 1.8 \\
\hline espd1 & 22 & 26 & 23,7 & 1,3 & 5,7 & 23 & 26 & 25,1 & 1.0 & 4,0 \\
\hline esped & 14 & 18 & 15,0 & 1,2 & 7.8 & 16 & 18 & 16,4 & 0.8 & 5.1 \\
\hline brqs & 4 & 6 & 5,0 & 0,5 & 9.2 & 5 & 6 & 5,3 & 0,5 & 8,8 \\
\hline brqi & 15 & 17 & 16,3 & 0.7 & 4,3 & 17 & 19 & 17,4 & 0,7 & 3,9 \\
\hline brat & 20 & 23 & 21,4 & 0,8 & 3,8 & 22 & 24 & 22,8 & 0,8 & 3.4 \\
\hline
\end{tabular}

pouco numerosos, 4 a 6 no ramo superior, 15 a 19 no inferior, totalizando 20 a 24 (Fig. 7B); holótipos de $O$. humensis e $O$. guazu com 20 rastros (4+16), parátipos com 18 a 21 totais. Vértebras, 26 pré-caudais, 21 a 23 caudais, totalizando 47 a 49; as primeiras vértebras caudais mantém o arco hemal expandido (urosoma) formando um funil hemal, por onde se prolonga a bexiga natatória.

Distribuição geográfica. Odontesthes humensis foi citada para o Rio Negro, Uruguai (DE BUEN 1953). Neste trabalho ampliou-se sua distribuição para o norte, até o Rio Jacui, afluente do Guaiba, Rio Grande do Sul, Brasil. Sua maior ocorrência foi nas lagoas costeiras Mirim e Mangueira, ao sul do Estado do Rio Grande do Sul (Fig. 1).

Revta bras. Zool. 19 (1): 251 - 287. 2002 
Variação intra-específica. A análise dos componentes principais foi realizada com 32 exemplares, sendo 23 da Lagoa Mirim e 9 da Lagoa Mangueira. O primeiro componente principal (cpl), explicou $90,7 \%$ da variação total com coeficientes positivos e de mesma magnitude (Tab. VI). Os coeficientes alométricos multivariados, indicaram que os caracteres olho $(\alpha=0,79)$, altped $(\alpha=0,80)$, juntamente com distâncias entre nadadeiras e pedúnculo caudal (anpc, p2pc) entre nadadeira (and2, pd1, ppl), tiveram alometria negativa, crescendo mais lentamente que o restante do corpo. E, distâncias entre nadadeiras (anp1, plp2, pl pc, d1 d2), pré-pélvica (pp2) e altura da cabeça, tiveram alometria positiva, crescendo mais rapidamente que o restante do corpo. Os caracteres cabeça, focinho, boca e maxila apresentaram isometria.

Tabela VI. Análise dos componentes principais para O. humensis (23 exemplares da Lagoa Mirim e 9 Lagoa Mangueira); matriz de variância-covariância total para 25 caracteres morfométricos transformados em logaritmos; (cp1) primeiro eixo extraído dos dados nāo ajustados; $(\alpha)$ coeficiente alométrico; coeficientes CP1 e CP2 obtidos com dados ajustados por projeçōes ortogonais.

\begin{tabular}{lcccc}
\hline \multicolumn{1}{c}{ Variáveis } & $c p 1$ & $\alpha$ & $C P 1$ & $C P 2$ \\
\hline cp & 0,201 & 1,01 & 0,027 & $-0,055$ \\
pd2 & 0,194 & 0,98 & $-0,014$ & $-0,094$ \\
pc1 & 0,186 & 0,94 & $-0,003$ & $-0,020$ \\
pan & 0,205 & 1,03 & $-0,110$ & 0,162 \\
pp2 & 0,237 & 1,19 & $-0,142$ & 0,093 \\
pp1 & 0,186 & 0,94 & $-0,010$ & 0,097 \\
cab & 0,192 & 0,97 & $-0,021$ & 0,099 \\
altcab & 0,242 & 1,22 & $-0,673$ & $-0,134$ \\
foc & 0,200 & 1,00 & $-0,148$ & 0,147 \\
olho & 0,158 & 0,79 & $-0,069$ & 0,456 \\
interorb & 0,188 & 0,95 & 0,139 & $-0,004$ \\
boca & 0,208 & 1,05 & $-0,037$ & $-0,049$ \\
max & 0,200 & 1,00 & $-0,190$ & $-0,067$ \\
altped & 0,159 & 0,160 & $-0,152$ \\
p1p2 & 0,80 & $-0,150$ & 0,037 \\
p1pc & 0,240 & 0,21 & 0,031 & $-0,098$ \\
p2pc & 0,201 & 0,076 & $-0,002$ \\
anpc & 0,186 & 0,94 & $-0,018$ \\
d1pc & 0,173 & 0,87 & 0,277 & $-0,183$ \\
d2pc & 0,195 & 0,98 & 0,407 & $-0,016$ \\
d1d2 & 0,192 & 0,97 & 0,008 & $-0,657$ \\
and1 & 0,224 & 1,13 & 0,180 & 0,010 \\
and2 & 0,196 & 0,99 & 0,150 & 0,103 \\
anp1 & 0,178 & 0,89 & 0,016 & 0,064 \\
anp2 & 0,219 & 1,10 & 18,300 & 16,600 \\
\hline Variância $(\%)$ & 0,211 & 1,06 & & \\
\hline
\end{tabular}

No conjunto de dados ajustados pelas projeções ortogonais, o primeiro componente principal explicou $18,3 \%$ e o segundo $16,6 \%$ da variação total, com coeficientes positivos e negativos, indicando aspectos da forma do corpo. O

Revta bras. Zool. 19 (1): $251-287,2002$ 
diagrama de dispersão dos pontos indicou, que apesar de retirada a influência do tamanho, os grupos continuaram sobrepondo-se, indicando não haver diferenças de forma entre os peixes coletados nas duas lagoas (Fig. 8). Do contraste de variáveis com coeficientes positivos (d2pc, dlpc, anpc) e coeficientes negativos (foram altcab, max, pl p2), nenhuma relação pode ser obtida, levando-se em consideração que as proporções corporais são muito semelhantes. Não foram observadas diferenças quanto a forma dos peixes obtidos nestas duas lagoas.

\section{Odontesthes incisa (Jenyns, 1842), comb. rev.}

Fig. 9A, Tab. VII

Atherina incisa Jenyns, 1842: 79 (localidade-tipo: Bahia Branca, Argentina).

Menidia uruguayensis Devincenzi, 1924: 205 (localidade-tipo: Rio da Prata, Uruguai); De Buen, 1950: 100.

Odontesthes incisus; Pozzi, 1945: 247.

Austroatherina incisa; Marrero, 1950: 11 5; De Buen, 1953: 70.

Sorgentinia incisa; Risso \& Risso, 1953.

Material examinado. Holótipo de Menidia uruguayensis MHNM 1804 (89mm cp) Rio de La Plata, Uruguay.

Outros espécimens examinados. BRASIL, Rio Grande do Sul: FURG 79.0543 (21) Rio Grande, Canal de Acesso 7 jul 1979; FURG 80.0229 (2) Rio Grande, 30 milhas ao norte do Canal de Acesso 17 jul 1980. ArgENTINA: MLP 13.XI.85.12 (12) Mar del Plata 13 nov 1985.

Diagnose. Odontesthes incisa distingue-se das demais espécies capturadas no sul do Brasil pela presença de 59 a 67 séries de escamas na linha longitudinal; peitorais curtas; opérculo não fenestrado no ângulo anterodorsal; vértebras caudais com arcos hemais expandidos, paredes laterais dos arcos hemais sem alargamento, formando um funil hemal incompleto (urosoma); bexiga natatória termina na cavidade visceral do corpo, sem penetrar nos arcos hemais.

Descrição. O comprimento padrão dos exemplares variou de 54 a $122 \mathrm{~mm}$. As relações morfométricas e merísticas encontram-se na tabela VII. Peixe de pequeno porte, não excedendo os $200 \mathrm{~mm}$ de comprimento total; corpo esbelto, semi transparente, dorso arredondado pouco comprimido, escamas grandes quadrangulares, bordo posterior com projeções irregularmente denteadas, crenuladas, cobrindo todo o corpo; cleitrum com escamas no bordo; três séries de escamas sub-oculares; sem escamas na base das nadadeiras. Cabeça de forma convexa no dorso 20,5 a 23,8 do comprimento padrão (cp); altura 10,1 a 13,8\% do cp. Boca estreita pouco protrátil 21,2 a $26,6 \%$ do comprimento da cabeça (cab); maxilar inclinado para baixo, chegando até a parte inferior da cabeça; dentes mandibulares pequenos dispostos irregularmente em uma só fileira; exceção para os dois laterais que são fortes, salientes, em forma de gancho dirigidos para baixo; dentes no vômer; raros no endopterigóide dos adultos. Focinho pontiagudo 31,3 a 35,7\% da cab; olhos superiores grandes, pigmentados 26,3 a $31,6 \%$ da cab; espaço inter-orbital reduzido 26,2 a $30,6 \%$ da cab, igual ao diâmetro do olho 26,3 a $31,6 \%$ da cab. Origem da primeira dorsal em cima do ânus ou posterior a cle; segunda dorsal inicia-se na 


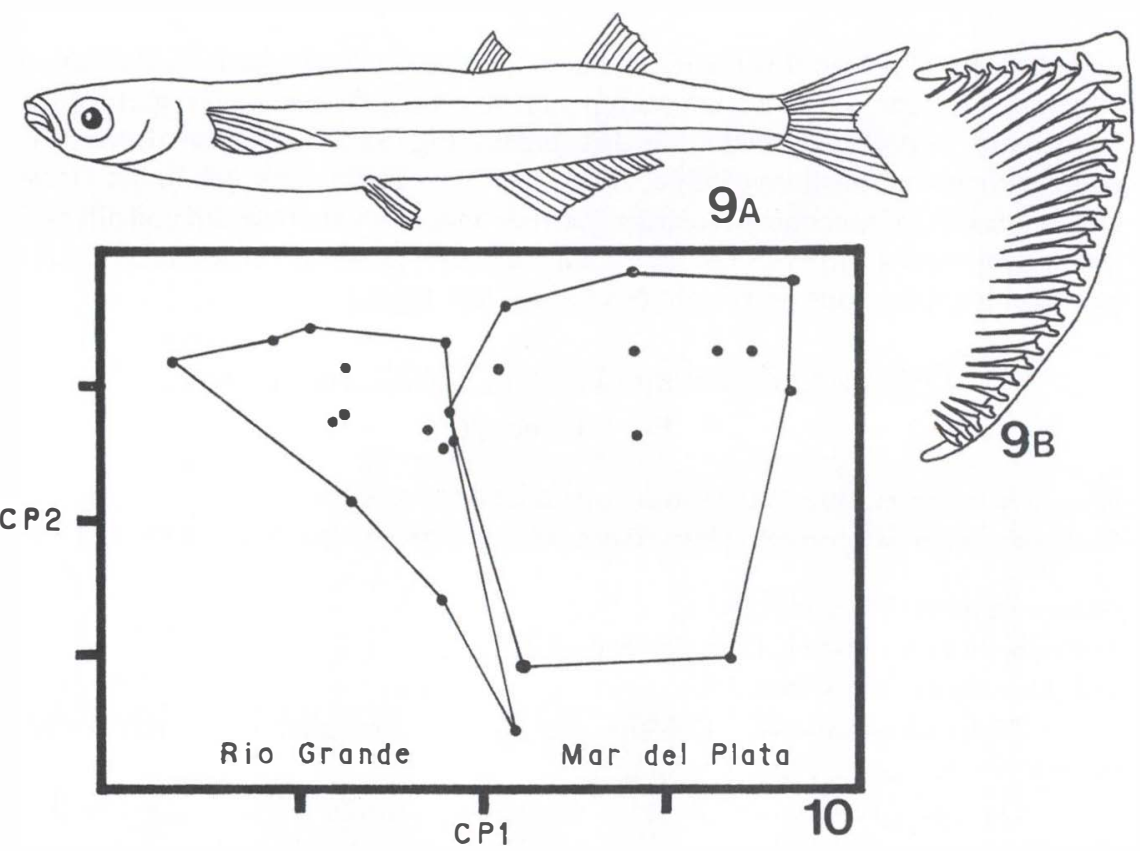

Figs 9-10. Odontesthes incisa. (9) Exemplar de $85 \mathrm{~mm}$ de comprimento padrāo (A) FURG 79.0543 barra de Rio Grande, Rio Grande do Sul, junho de 1979, (B) primeiro arco branquial esquerdo; (10) projeçāo dos escores individuais de exemplares, no espaço dos dois primeiros componentes principais (CP1, CP2), para 25 caracteres morfométricos; dados ajustados com projeçōes ortogonais de Burnaby.

vertical que passa pelo $11^{\circ}$ raio anal, terminando posteriormente à nadadeira anal. Extremidade distal das peitorais, apoiadas à superfície do corpo, não alcança a origem das pélvicas, faltando sete escamas; pélvicas bem separadas entre si, com pequena escama axilar. Dorsal IV a VI e 8 a 11 raios; anal 16 a 20 raios; linha longitudinal com 59 a 67 séries de escamas, das quais 24 a 30 estão localizadas anteriormente a primeira dorsal. Rastros do primeiro arco branquial com 5 a 6 no ramo superior, 22 a 30 no inferior, totalizando 27 a 35 (Fig. 9B). Vértebras: 19 pré-caudais, 25 a 26 caudais, totalizando 44 a 45 ; os arcos hemais das primeiras vértebras caudais são expandidos, porém suas paredes laterais não são alargadas, tornando o funil hemal (urosoma) incompleto; a bexiga natatória não se prolonga por entre os arcos hemais. Possui intensa concentração de cromatóf oros, que lhe dá um aspecto escurecido, de cor negra.

Distribuição geográfica. Odontesthes incisa é uma espécie de mar aberto, capturada geralmente fora da costa; MARRERO (1950) citou sua ocorrência no litoral Atlântico desde Bahia Blanca $\left(39^{\circ} \mathrm{S}\right)$ até o Estreito de Magalhães $\left(52^{\circ} \mathrm{S}\right)$; LAHILLE (1929) e RiSSO \& Risso (1953) citaram-na para a costa de Mar del Plata (38º), Argentina. Neste trabalho foram revisados exemplares desde Tramandaí $\left(30^{\circ} \mathrm{S}\right)$, Brasil, até Mar del Plata ( $35^{\circ}$ S), Argentina (Fig. 1). 
Variação intra-específica. A análise dos componentes principais foi realizada com 12 exemplares coletados em Mar del Plata, Argentina e 13 de Rio Grande, Brasil. O primeiro componente principal (cpl), explicou 94,2\% da variação total com coeficientes positivos e de semelhante magnitude (Tab. VIII). Os coeficientes alométricos multivariados, indicaram que os caracteres boca $(\alpha=0,76)$ e altura do pedúnculo ( $\alpha=0,77$ ), juntamente com olho, inter-orbital, altura da cabeça e distância entre nadadeiras (and1, and2), tem alometria negativa, crescendo mais lentamente que o restante do corpo. E, as distâncias pré-dorsais, pré-anal (pdl, pd2, pan), distâncias entre nadadeiras (anpl, anp2), distâncias entre nadadeiras e o pedúnculo caudal (d1pc, d2pc, p2pc, plpc), apresentaram alometrias positivas, crescendo mais rapidamente que o restante do corpo (Tabs. VII e VIII).

Tabela VII. Dados comparativos dos caracteres morfométricos e merísticos de duas populaçōes de $O$. incisa. Medidas expressas como percentagens do comprimento padrāo e comprimento da cabeça; (cv) coeficiente de variação.

\begin{tabular}{|c|c|c|c|c|c|c|c|c|c|c|}
\hline \multirow{2}{*}{ Variáveis } & \multicolumn{5}{|c|}{ Rio Grande $(n=13)$} & \multicolumn{5}{|c|}{ Mar del Plata $(n=12)$} \\
\hline & Min & Máx & Méd & Des & cv & Min & Máx & Méd & Des & cv \\
\hline $\mathrm{cp}(\mathrm{mm})$ & 69 & 122 & & & & 54 & 94 & & & \\
\hline \multicolumn{11}{|c|}{ Percentagem do comprimento padrão } \\
\hline pd1 & 52,8 & 58,5 & 55,6 & 1,64 & 2,95 & 53,8 & 57,5 & 55,8 & 1,14 & 2,04 \\
\hline pd2 & 69,2 & 74,6 & 71,9 & 1,44 & 2,00 & 69,7 & 73,9 & 71,9 & 1,39 & 1,93 \\
\hline pan & 58,0 & 62,2 & 60.4 & 1,42 & 2,35 & 58,5 & 61,8 & 59,7 & 0,90 & 1,51 \\
\hline pp1 & 23,3 & 25,4 & 24.2 & 0,73 & 3,00 & 23,1 & 25,8 & 24,1 & 0,73 & 3,01 \\
\hline pp2 & 42,0 & 46,4 & 44,2 & 1,08 & 2,44 & 41.9 & 45,9 & 43,8 & 1,14 & 2,60 \\
\hline$c a b$ & 21,2 & 23,8 & 22,4 & 0,78 & 3,50 & 20,5 & 22,2 & 21,5 & 0,53 & 2,48 \\
\hline altcab & 11,1 & 13,8 & 12,4 & 0,75 & 6,00 & 10,1 & 12,2 & 11,1 & 0,56 & 5,09 \\
\hline foc & 7,2 & 8,0 & 7,7 & 0,28 & 3,65 & 6,4 & 7,7 & 7,1 & 0,36 & 5,13 \\
\hline altped & 7,0 & 8,3 & 7,4 & 0,38 & 5,06 & 5,5 & 6,8 & 6,2 & 0,41 & 6,51 \\
\hline p1p2 & 20,5 & 23,5 & 22,2 & 0,85 & 3,84 & 19,6 & 23,2 & 21,4 & 0,92 & 4,30 \\
\hline p1pc & 74,6 & 78,6 & 76,5 & 1,14 & 1,48 & 73,1 & 78,1 & 75,8 & 1,39 & 1,83 \\
\hline p2pc & 54,9 & 58,3 & 56,9 & 0,96 & 1,68 & 52,6 & 58,8 & 56,1 & 2,12 & 3,77 \\
\hline anpc & 39,3 & 42,0 & 40,4 & 0,81 & 2,01 & 38,5 & 42,3 & 40,2 & 1,08 & 2,68 \\
\hline d1pc & 42,6 & 47,9 & 44,7 & 1,52 & 3,40 & 42,9 & 46,2 & 44,4 & 1,01 & 2,28 \\
\hline d2pc & 26,9 & 29,8 & 28,6 & 0,88 & 3,09 & 26,3 & 30,1 & 28,0 & 1,13 & 4,05 \\
\hline d1d2 & 15,5 & 19,4 & 17,5 & 1,05 & 5,99 & 15,8 & 18,9 & 16,9 & 0,88 & 5,19 \\
\hline and1 & 13,6 & 15,9 & 15,1 & 0,76 & 5,02 & 11,8 & 14,1 & 12,9 & 0,88 & 6,80 \\
\hline and2 & 17,1 & 19,4 & 18,2 & 0,67 & 3,66 & 15,5 & 18,9 & 16,9 & 1,03 & 6,08 \\
\hline anp1 & 36,0 & 40,5 & 38,3 & 1,39 & 3,64 & 36,1 & 40,2 & 37,5 & 1,22 & 3,26 \\
\hline anp2 & 15,9 & 21,8 & 17.7 & 1,82 & 10,28 & 15,3 & 21,5 & 17,5 & 1,94 & 11,08 \\
\hline \multicolumn{11}{|c|}{ Percentagem do comprimento da cabeça } \\
\hline foc & 31,3 & 35,7 & 34,3 & 1,18 & 3,45 & 31,3 & 35,3 & 32,8 & 1,23 & 3,74 \\
\hline olho & 26,3 & 29,4 & 28,3 & 0,97 & 3,43 & 27,2 & 31,6 & 28,7 & 1,36 & 4,76 \\
\hline interorb & 26,2 & 30,6 & 28,4 & 1,23 & 4,32 & 26,5 & 30,1 & 28,0 & 1,24 & 4,42 \\
\hline boca & 21,9 & 25,8 & 23,5 & 1,26 & 5,36 & 21,2 & 26,6 & 24,4 & 1,73 & 7,07 \\
\hline $\max$ & 30,8 & 36,8 & 34,2 & 1,73 & 5,05 & 30,7 & 36,7 & 32,9 & 1,93 & 5,89 \\
\hline \multicolumn{11}{|l|}{ Contagens } \\
\hline d1 & 4 & 6 & 4,8 & 0,6 & 11,4 & 4 & 6 & 5,0 & 0,6 & 11,5 \\
\hline d2 & 8 & 11 & 9,3 & 0,8 & 8,8 & 8 & 9 & 8,5 & 0,5 & 5,9 \\
\hline an & 16 & 20 & 18.0 & 1,2 & 6,5 & 16 & 19 & 17,5 & 1,0 & 5,5 \\
\hline and2 & 9 & 12 & 10,5 & 0,8 & 8.1 & 10 & 11 & 10,5 & 0,5 & 4,8 \\
\hline p1 & 12 & 15 & 13,1 & 0,6 & 4,7 & 13 & 13 & 13,0 & 0,0 & 0,0 \\
\hline eslong & 59 & 65 & 61,5 & 1,7 & 2,8 & 60 & 67 & 64,0 & 2,1 & 3,3 \\
\hline espd1 & 24 & 27 & 25.6 & 1.0 & 3,9 & 25 & 30 & 28.0 & 1,9 & 6,7 \\
\hline esped & 14 & 16 & 15,4 & 0,9 & 6,0 & & & & & \\
\hline bras & 5 & 6 & 5,2 & 0,4 & 8,1 & 5 & 5 & 5,0 & & \\
\hline brai & 22 & 26 & 24,2 & 1,2 & 5,2 & 26 & 30 & 28,7 & 1,9 & 6,6 \\
\hline brat & 27 & 31 & 29,5 & 1,3 & 4,3 & 31 & 35 & 33.7 & 1,9 & 5,6 \\
\hline
\end{tabular}


Tabela VIII. Análise dos componentes principais para O. incisa (13 exemplares de Rio Grande, Brasil, 12 Mar del Plata, Argentina); matriz de variância-covariância total para 25 caracteres morfométricos transformados em logaritmos; (cp1) primeiro eixo extraído dos dados nāo ajustados; $(\alpha)$ coeficiente alométrico; coeficientes CP1 e CP2 obtidos com dados ajustados por projeçōes ortogonais.

\begin{tabular}{lcccc}
\hline \multicolumn{1}{c}{ Variáveis } & $c p 1$ & $\alpha$ & $C P 1$ & $C P 2$ \\
\hline cp & 0,216 & 1,06 & 0,138 & 0,110 \\
pd2 & 0,214 & 1,08 & 0,159 & 0,190 \\
pc1 & 0,212 & 1,07 & 0,196 & 0,062 \\
pan & 0,125 & 1,08 & 0,119 & 0,197 \\
pp2 & 0,206 & 1,04 & 0,154 & 0,190 \\
pp1 & 0,200 & 1,01 & 0,149 & $-0,093$ \\
cab & 0,204 & 1,03 & $-0,031$ & $-0,025$ \\
altcab & 0,186 & 0,94 & $-0,361$ & 0,147 \\
foc & 0,202 & 1,01 & 0,205 \\
olho & 0,171 & 0,86 & $-0,175$ & 0,112 \\
interorb & 0,161 & $-0,047$ & 0,126 \\
boca & 0,151 & 0,76 & 0,089 & $-0,072$ \\
max & 0,195 & 0,98 & 0,001 \\
altped & 0,154 & 0,77 & $-0,208$ & $-0,005$ \\
p1p2 & 0,210 & 1,06 & $-0,020$ & $-0,036$ \\
p1pc & 0,219 & 0,10 & 0,048 \\
p2pc & 0,220 & 1,11 & 0,153 & 0,002 \\
anpc & 0,203 & 1,02 & $-0,051$ \\
d1pc & 0,214 & 1,08 & 0,176 & 0,030 \\
d2pc & 0,213 & 1,07 & 0,125 & $-0,123$ \\
d1d2 & 0,187 & 0,94 & 0,066 & $-0,033$ \\
and1 & 0,181 & 0,91 & $-0,018$ & $-0,872$ \\
and2 & 0,184 & 0,93 & $-0,517$ & 18,900 \\
anp1 & 0,225 & 1,13 & $-0,216$ & 0,028 \\
anp2 & 0,235 & 1,18 & 0,152 & \\
\hline Variância $(\%)$ & 94,200 & & 34,400 & \\
\hline
\end{tabular}

No conjunto de dados ajustados pelas projeções ortogonais, os dois primeiros eixos representaram $34,4 \%$ e $18,9 \%$, respectivamente da variância total, com coeficientes positivos e negativos, indicando aspectos da forma do corpo. No diagrama de dispersão dos pontos, observa-se a formação de distintos grupos entre Rio Grande, Brasil e Mar del Plata, Argentina (Fig. 10). Este padrão de diferenciação representa o contraste entre duas séries de variáveis. As de coeficiente positivos (pdl, anpc, pd2, anp2) estiveram relacionadas com as medidas longitudinais do peixe, apresentando semelhantes médias nas proporções corporais dos dois grupos. Aquelas de coeficientes negativos (and1, altped, altcab, and2), representaram as medidas tomadas obliquamente no peixe, identificando o crescimento diferenciado na altura, com proporções corporais médias relativamente maiores nos exemplares de Rio Grande (Tab. VII).

\section{Odontesthes mirinensis Bemvenuti, 1995}

Fig. $11 \mathrm{~A}$, Tab. IX

Odontesthes mirinensis Bemvenuti 1995: 885 (localidade-tipo: Lagoa Mirim, Taim, Rio Grande do Sul).

Material examinado. Holótipo MCP 17696 (109 mm cp) Lagoa Mirim, Taim, Rio Grande do Sul, 29 dez 1988; parátipos FURG 88.0002 (48) 105 à 140 mm cp Lagoa Mirim, Rio Grande do Sul, 29 dez 1988.

Revta bras. Zool. 19 (1): 251 - 287, 2002 


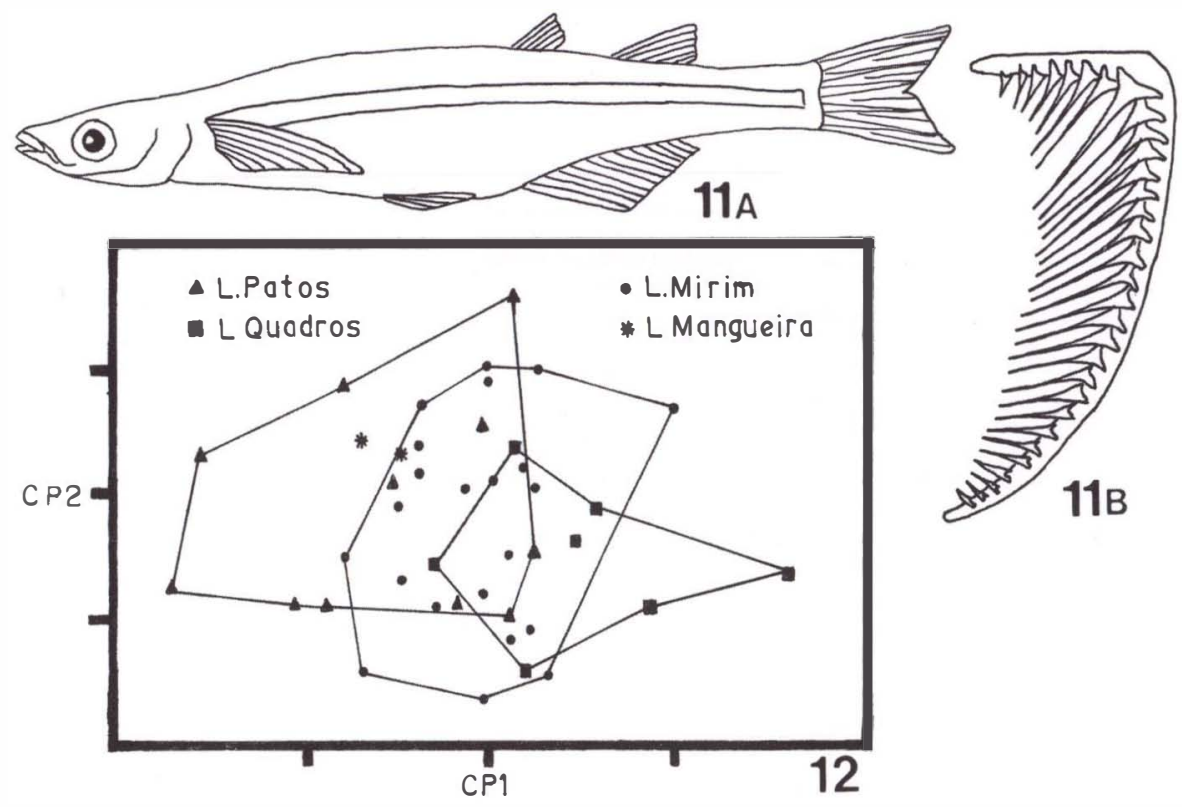

Figs 11-12. Odontesthes mirinensis. (11) Exemplar de $124 \mathrm{~mm}$ de comprimento padrāo (A) FURG 93.0001 Canal Sāo Gonçalo, Pelotas, Rio Grande do Sul, fevereiro de 1993, (B) primeiro arco branquial esquerdo; (12) projeçāo dos escores individuais de 46 exemplares de $O$. mirinensis, no espaço dos dois primeiros componentes principais (CP1, CP2), para 25 caracteres morfométricos; dados ajustados com projeçōes ortogonais de Burnaby.

Outros espécimens examinados. BRASIL, Rio Grandedo Sul: FURG 86.0024 (28) Lagoa dos Quadros, Osório, set 1986; FURG 87.0017 (7) Lagoa Mirim, Rio Grande, 18 jul 1987; FURG 87.0042 (2) idem, jul 1987; FURG 87.0052 (1) Lagoa dos Patos, Butiá, 15 dez 1987; FURG 87.0053 (3) Lagoa dos Patos, Tapes, 18 dez 1987; FURG 87.0061 (4) Arroio del Rei, Lagoa Mirim, 4 nov 1987; FURG 87.0062 (1) Lagoa dos Patos, Tapes, 14 dez 1987; FURG 87.0063 (25) Lagoa Mirim, Bosque, 20 out 1987; FURG 87.0064 (39) Lagoa Mirim, Taim, 5 out 1987; FURG 88.0005 (1) Lagoa dos Patos, Tapes, 5 jun 1988; FURG 90.0002 (11) Lagoa Mirim, 2 mai 1990; FURG 92.0002 (1) Lagoa Mangueira, ago 1992; FURG 92.0003 (1) idem, 1 out 1992; FURG 92.0004 (13) Canal São Gonçalo, Pelotas, out 1992; FURG 92.0008 (16) Lagoa Fortaleza, Cidreira, 15 jan 1992; FURG 93.0001 (12) Canal São Gonçalo, Pelotas, fev 1993; FURG 93.0002 (8) idem, mar 1993; MCP 10.573 (3) Rio Guaíba, Porto Alegre, 22 ago 1985; MCP 10.579 (2) Lagoa dos Patos, Camaquã 20 out 1985.

Diagnose. Odontesthes mirinensis distingue-se das demais espécies capturadas no extremo sul do Brasil, pela presença de 31 a 37 rastros no primeiro arco branquial, sobrepondo-se a $O$. argentinensis (27 a 33) e $O$. aff. perugiae (30 a 37). Difere destas pelo número de rastros no ramo inferior do primeiro arco branquial 24 a 29 contra 20 a $24 \mathrm{em} O$. argentinensis e pelo focinho curto 6,1 a 7,9\% contra 8,2 a $10,7 \%$ do cp em $O$. aff. perugiae. 
Tabela IX. Dados comparativos dos caracteres morfométricos e merísticos de três populaçōes de $O$. mirinensis. Medidas expressas em percentagens do comprimento padrão e comprimento da cabeça; (cv) coeficiente de variação.

\begin{tabular}{|c|c|c|c|c|c|c|c|c|c|c|c|c|c|c|c|}
\hline \multirow{2}{*}{ Variáveis } & \multicolumn{5}{|c|}{ Lagoa dos Quadros ( $n=7)$} & \multicolumn{5}{|c|}{ Lagoa Mirim ( $n=22$ ) } & \multicolumn{5}{|c|}{ Lagoa dos Patos $(n=11)$} \\
\hline & Min & Máx & Méd & Des & cv & Min & Máx & Méd & Des & $\mathrm{cv}$ & Min & Máx & Méd & Des & $\mathrm{cv}$ \\
\hline $\mathrm{cp}(\mathrm{mm})$ & 129 & 164 & & & & 95 & 148 & & & & 100 & 225 & & & \\
\hline \multicolumn{16}{|c|}{ Percentagem do comprimento padrāo } \\
\hline pd1 & 58,8 & 61,7 & 59,9 & 1,1 & 1,9 & 59,9 & 63,8 & 61,4 & 1,0 & 1,7 & 59,0 & 64,4 & 62,2 & 1,6 & 2,6 \\
\hline pd2 & 72,2 & 75,1 & 73,9 & 0,8 & 1,1 & 72,6 & 76,5 & 74,4 & 1,0 & 1,3 & 72,1 & 76,8 & 74,7 & 1,5 & 2,0 \\
\hline pan & 63,6 & 65,2 & 64,4 & 0,5 & 0,8 & 62,1 & 67,6 & 65,2 & 1,5 & 2,2 & 62,7 & 67,3 & 65,0 & 1,7 & 2,6 \\
\hline pp1 & 24,0 & 26,2 & 24,7 & 0,7 & 3,0 & 21,9 & 25,7 & 24,1 & 1,0 & 4,0 & 22,0 & 25,9 & 24,3 & 0,9 & 3,9 \\
\hline pp2 & 43,9 & 48,4 & 45,9 & 1,4 & 3,0 & 44,9 & 48,2 & 46,6 & 0,9 & 1,9 & 44,0 & 48,7 & 46,1 & 1,4 & 3,1 \\
\hline$c a b$ & 21,8 & 23,6 & 22,8 & 0,6 & 2,7 & 20,5 & 23,9 & 22,5 & 0,9 & 3,8 & 21,0 & 23,2 & 22,6 & 0,6 & 2,8 \\
\hline altcab & 11,4 & 13,2 & 12,6 & 0,7 & 5,2 & 11,3 & 14,3 & 12,3 & 0,7 & 5,8 & 11,8 & 13,8 & 12,5 & 0,5 & 4,1 \\
\hline foc & 6,6 & 7,6 & 6,9 & 0,4 & 5,2 & 6,3 & 7,5 & 6,8 & 0,3 & 4,6 & 6,7 & 7,6 & 7.1 & 0.3 & 3,6 \\
\hline altped & 7,9 & 8,6 & 8,3 & 0,2 & 2,6 & 6,9 & 9,1 & 8,1 & 0,5 & 6,3 & 7,6 & 9,6 & 8,3 & 0,6 & 7,0 \\
\hline p1p2 & 21,3 & 25,0 & 24,0 & 1,2 & 4,8 & 22,7 & 26,5 & 24,5 & 1,1 & 4.4 & 22,6 & 26,0 & 24,4 & 1,0 & 4,0 \\
\hline p1pc & 75,6 & 78,1 & 76,5 & 0,9 & 1,2 & 75,5 & 78,9 & 77,2 & 0,8 & 1.0 & 76,0 & 79,0 & 77,5 & 1,1 & 1,4 \\
\hline p2pc & 55,7 & 59,6 & 57,7 & 1,2 & 2,1 & 55,5 & 58,8 & 56,8 & 0,9 & 1,5 & 56,0 & 60,1 & 58,1 & 1,4 & 2,4 \\
\hline anpc & 36,6 & 41,5 & 39,1 & 1,7 & 4,4 & 35,8 & 38,9 & 37,5 & 0,8 & 2,3 & 37,2 & 40,2 & 38,5 & 1,0 & 2,5 \\
\hline d1pc & 39,0 & 41,9 & 39,9 & 1,0 & 2,4 & 36,3 & 41,0 & 39,1 & 1,2 & 3,2 & 37,8 & 40,9 & 39,4 & 1,0 & 2,5 \\
\hline d2pc & 26,2 & 27,8 & 27,0 & 0,6 & 2,1 & 24,2 & 29,6 & 26,5 & 1,2 & 4,6 & 25,7 & 28,7 & 27,3 & 0,9 & 3,2 \\
\hline d1d 2 & 13,1 & 15,7 & 13,9 & 0,9 & 6,2 & 11,3 & 15,8 & 13,1 & 1,0 & 7,7 & 11,1 & 14,2 & 12,6 & 1,0 & 7,6 \\
\hline and 1 & 17,0 & 18,6 & 17,6 & 0,6 & 3,3 & 16,5 & 19,6 & 18,4 & 0,8 & 4,4 & 16,8 & 20,0 & 18,1 & 1,2 & 6,4 \\
\hline and2 & 19,5 & 21,3 & 20,2 & 0,6 & 2,7 & 18,9 & 22,8 & 20,8 & 1,0 & 5,0 & 19,2 & 22,3 & 20,9 & 1,0 & 4,8 \\
\hline anp1 & 39,6 & 42,8 & 41,8 & 1,2 & 2,8 & 40,2 & 44,4 & 42,7 & 1,2 & 2,7 & 39,2 & 43,6 & 41,7 & 1,4 & 3,3 \\
\hline anp2 & 17,6 & 21,5 & 19,9 & 1,1 & 5,6 & 17,4 & 22,3 & 19,9 & 1,3 & 6,3 & 17,0 & 21,3 & 19,5 & 1,4 & 7,2 \\
\hline \multicolumn{16}{|c|}{ Percentagem do comprimento da cabeça } \\
\hline foc & 29,2 & 32,0 & 30,5 & 1,0 & 3,4 & 28,1 & 32,9 & 30,4 & 1,4 & 4,5 & 30,3 & 33,3 & 31,3 & 1,0 & 3,3 \\
\hline olho & 22,4 & 27,8 & 25,2 & 2,1 & 8,3 & 23,3 & 29,2 & 26,5 & 1,8 & 6,8 & 18,2 & 29,2 & 24,7 & 3,3 & 13,3 \\
\hline interorb & 25,2 & 31,5 & 27,5 & 2,0 & 7,3 & 25,0 & 30,4 & 28,0 & 1,5 & 5,2 & 26,2 & 30,8 & 28,6 & 1,4 & 4,9 \\
\hline boca & 23,2 & 29,0 & 26,6 & 2,1 & 7,8 & 22,8 & 29,2 & 25,0 & 1,6 & 6,3 & 23,5 & 28,8 & 25,6 & 1,5 & 5,8 \\
\hline $\max$ & 31,0 & 35,0 & 32,7 & 1,6 & 4,9 & 29,6 & 35,9 & 33,2 & 1,8 & 5,3 & 30,4 & 35,2 & 33,6 & 1,3 & 3,9 \\
\hline \multicolumn{16}{|c|}{ Contagens } \\
\hline d1 & 4 & 5 & 4,1 & 0,3 & 8,4 & 3 & 6 & 4,5 & 0,7 & 15,7 & 3 & 5 & 3,9 & 0,7 & 17,1 \\
\hline d2 & 8 & 9 & 8,1 & 0,3 & 4,3 & 8 & 10 & 8,8 & 0,5 & 6,2 & 8 & 9 & 8,5 & 0,5 & 5,9 \\
\hline an & 14 & 17 & 15,4 & 0,9 & 5,9 & 15 & 17 & 15,9 & 0,5 & 3,4 & 15 & 18 & 15,9 & 0,9 & 5,7 \\
\hline and2 & 9 & 10 & 9,1 & 0,3 & 3,8 & 9 & 11 & 10,1 & 0,5 & 4,7 & 9 & 11 & 9,6 & 0,7 & 7,2 \\
\hline p1 & 12 & 13 & 12,7 & 0,5 & 3,6 & 12 & 13 & 12,4 & 0,5 & 4,0 & 13 & 13 & 13,0 & 0,0 & 0,0 \\
\hline eslong & 47 & 52 & 50,0 & 1,5 & 3,0 & 46 & 52 & 48,6 & 1,6 & 3,3 & 48 & 52 & 49,5 & 1,3 & 2,6 \\
\hline espd1 & 20 & 25 & 22,6 & 1,6 & 7,0 & 20 & 23 & 21,2 & 1,1 & 5,0 & 21 & 22 & 21,6 & 0,5 & 2,3 \\
\hline esped & 14 & 16 & 14,6 & 0,9 & 6,2 & 14 & 16 & 14,1 & 0,5 & 3,3 & 14 & 16 & 15,3 & 1,0 & 6,3 \\
\hline brqs & 6 & 9 & 7,9 & 0,8 & 10,6 & 6 & 8 & 7,3 & 0,7 & 9,1 & 6 & 8 & 7,3 & 0,7 & 10,3 \\
\hline brai & 24 & 29 & 26,0 & 1,5 & 5,8 & 25 & 29 & 27,4 & 1,2 & 4,3 & 24 & 29 & 26,8 & 1,6 & 6,1 \\
\hline brat & 31 & 37 & 33,9 & 1,9 & 5,6 & 31 & 37 & 34,5 & 1,6 & 4,7 & 31 & 37 & 34,2 & 2,0 & 6,0 \\
\hline
\end{tabular}

Descrição. O comprimento padrão dos exemplares examinados variou de 65,5 a $225 \mathrm{~mm}$. As relações morfométricas e merísticas encontram-se na tabela IX. Corpo alto, relativamente curto, recoberto por escamas grandes ciclóides com bordo posterior irregular; três séries de escamas sub-oculares; cleitrum sem escamas no bordo. Cabeça pequena 20,5 a 24\% do comprimento padrão (cp). Focinho curto 28,1 a 33,3\% do comprimento da cabeça (cab); distância inter-orbital 24 a 32\% da cab; (24,6\% nos peixes pequenos e 31 a 32\% nos maiores); olhos grandes 22 a $29 \%$ da cab; (diminuindo nos adultos 18 a 19\%); boca protrátil com largura entre 22,8 e $30 \%$ da cab; maxila e mandíbula em mesma projeção anterior; dentes mandibulares dispostos irregularmente em duas fileiras; vômer sem dentes; endopterigóides com

Revta bras. Zool. 19 (1): $251-287,2002$ 
placa de dentes. Origem da primeira dorsal em cima do ânus ou posterior a ele; segunda dorsal origina-se sobre a vertical que passa entre o $9^{\circ}$ e $11^{\circ}$ raios da nadadeira anal, terminando ambas na mesma vertical. Extremidade distal das nadadeiras peitorais, apoiadas à superfície do corpo, alcança a origem das nadadeiras pélvicas; origem das pélvicas distante da origem da anal, cerca de sete séries de escamas; pélvicas muito juntas, alguns exemplares com membrana inter-pélvica. Dorsal III a VI e 8 a 10 raios; anal 14 a 18 raios; linha longitudinal com 46 a 52 séries de escamas das quais 20 a 25 estão localizadas anteriormente à primeira dorsal. Rastros do primeiro arco branquial finos, compridos 6 a 9 no ramo superior, 24 a 29 no inferior, totalizando 31 a 37 (Fig. 11B). Vértebras: 25 pré-caudais, 21 a 23 caudais, totalizando 46 a 48; as primeiras vértebras caudais (cerca de 8 ou 9), possuem o arco hemal expandido formando um tubo hemal, por onde se prolonga a bexiga natatória; as paredes dos arcos hemais são bastante alargadas mantendo-os próximos um do outro.

Distribuição geográfica. Odontesthes mirinensis foi coletada desde a Lagoa dos Quadros até as lagoas Mirim e Mangueira, incluindo lagoas menores de Cerquinha, Fortaleza e outras. Sua maior abundância foi registrada na Lagoa Mirim com muitos indivíduos juvenis, atingindo a área do Canal São Gonçalo, Pelotas (BEMVENUTI 1995) (Fig. 1).

Variação intra-específica. A análise dos componentes principais foi realizada com 2 exemplarescoletados na Lagoa Mangueira, 22 na Lagoa Mirim, 7 na Lagoa dos Quadros e 11 na Lagoa dos Patos (Camaquã, Tapes e Canal São Gonçalo, Pelotas). O primeiro componente principal (cpl), explicou $96,4 \%$ da variação total com coeficientes positivos e de semelhante magnitude (Tab. X). Os coeficientes alométricos multivariados, indicaram que o caráter olho $(\alpha=0,54)$, juntamente com a maxila, distância pré-anal, pré-pélvica (pan, pp2) e distância entre nadadeiras (p1p2), tem alometria negativa, crescendo mais lentamente que o restante do corpo. E, altura da cabeça, focinho, boca, distância pré-peitoral ( $\mathrm{ppl}$ ), distância entre nadadeiras (dld2) e distância entre nadadeiras e o pedúnculo caudal (dlpc), tem alometria positiva, crescendo mais rapidamente que o restante do corpo (Tab. X).

No con juntode dados ajustados pelas projeções ortogonais, os dois primeiros eixos representaram $19,9 \%$ e $14,1 \%$, respectivamente da variância total, com coeficientes positivos e negativos, indicando aspectos da forma do corpo. O diagrama de dispersão dos pontos, evidenciou uma sobreposição entre os grupos amostrados. Os peixes da Lagoa Mirim tiveram uma disposição mais central no gráfico, enquanto os indivíduos da Lagoa dos Quadros formaram um grupo mais à direita e os da Lagoa dos Patos mais à esquerda (Fig. 12). A proximidade entre os agrupamentos da Lagoa Mirim e Lagoa dos Patos se deve, provavelmente, ao fato de que a maioria dos indivíduos foram coletados no Canal São Gonçalo, que liga as duas lagoas. Este padrão de diferenciação esteve representado pelo contraste entre duas séries de variáveis. As de coeficientes positivos ( $\mathrm{d} l \mathrm{~d} 2$, olho, anp2) e as de coeficientes negativos (intorb, and 1 , foc, max) (Tab. X). Não foram observadas variações nas médias das proporções corporais entre cabeça e região posterior, segundo este contraste de variáveis. Considerando-se a forma dos peixes, os grupos não foram discriminados conforme os locais amostrados (Tab. IX). 
Tabela X. Análise dos componentes principais para 0 . mirinensis (2 exemplares da Lagoa Mangueira, 22 Lagoa Mirim, 7 Lagoa Quadros, 11 Lagoa dos Patos); matriz de variância-covariância total para 25 caracteres morfométricos transformados em logaritmos; (cp1) primeiro eixo extraído dos dados nāo ajustados; $(\alpha)$ coeficiente alométrico; coeficientes CP1 e CP2 obtidos com dados ajustados por projeçōes ortogonais.

\begin{tabular}{lcccc}
\hline \multicolumn{1}{c}{ Variáveis } & $\mathrm{cp1}$ & $\alpha$ & $\mathrm{CP} 1$ & $\mathrm{CP} 2$ \\
\hline $\mathrm{cp}$ & 0,196 & 0,98 & $-0,003$ & 0,023 \\
$\mathrm{pd2}$ & 0,202 & 1,02 & $-0,060$ & 0,024 \\
$\mathrm{pc1}$ & 0,197 & 0,99 & $-0,129$ & 0,062 \\
$\mathrm{pan}$ & 0,192 & 0,96 & $-0,025$ & 0,071 \\
$\mathrm{pp2}$ & 0,194 & 0,97 & $-0,064$ & $-0,031$ \\
$\mathrm{pp1}$ & 0,209 & 1,05 & $-0,075$ & $-0,238$ \\
$\mathrm{cab}$ & 0,207 & 1,04 & $-0,118$ & $-0,177$ \\
altcab & 0,226 & 1,14 & 0,013 & $-0,022$ \\
foc & 0,212 & 1,07 & $-0,198$ & $-0,008$ \\
olho & 0,107 & 0,54 & 0,536 & $-0,401$ \\
interorb & 0,206 & 1,04 & $-0,241$ & $-0,191$ \\
ooca & 0,220 & 1,10 & 0,074 & $-0,291$ \\
max & 0,185 & 0,93 & $-0,163$ & $-0,113$ \\
altped & 0,201 & 1,01 & $-0,127$ & $-0,280$ \\
p1p2 & 0,193 & 0,97 & $-0,043$ & 0,215 \\
p1pc & 0,199 & 1,00 & $-0,015$ & 0,084 \\
p2pc & 0,204 & 1,03 & 0,013 & 0,171 \\
anpc & 0,203 & 1,02 & 0,066 & 0,097 \\
d1pc & 0,207 & 1,04 & 0,085 & $-0,005$ \\
d2pc & 0,196 & 0,98 & 0,027 & $-0,090$ \\
d1d2 & 0,217 & 1,09 & 0,556 & 0,084 \\
and1 & 0,200 & 1,01 & $-0,201$ & 0,063 \\
and2 & 0,199 & $-0,108$ & 0,251 \\
anp1 & 0,200 & 0,068 & 0,569 \\
anp2 & 0,203 & 1,01 & 0,377 & 14,100 \\
\hline Variância (\%) & 96,400 & 1,02 & 16,900 & \\
\hline
\end{tabular}

\title{
Odontesthes aff. perugiae Evermann \& Kendall, 1906
}

\author{
Fig. 13A, Tab. XI
}

Odontesthes perugiae Evermann \& Kendall, 1906: 94 (localidade-tipo Argentina).

Odontesthes orientalis De Buen, 1950: 149 (localidade-tipo Embalse del Rio Negro, Uruguay 17 jul 1947).

Material examinado. Holótipo de Odontesthes perugiae USNM 55572 (114 mm cp) Argentina; holótipo de Odontesthes orientalis MHNM 1808 (107 $\mathrm{mm} \mathrm{cp}$ ) Embalse del Rio Negro - Bañado de Legrand - Durazno, Uruguay 17 jul 1947.

Outros espécimens examinados. BRASIL, Rio Grande do Sul:FURG 87.0019 (1) Lagoa Mangueira, 20 ago 1987; FURG 87.0020 (1) idem, jul 1987; FURG 87.0021 (1) ibidem, out 1987; FURG 87.0022 (1) Lagoa Mirim, 31 jul 1987; FURG 87.0023 (1) idem, 26 jun 1987; FURG 87.0024 (1) Lagoa Mangueira, jul 1987; FURG 87.0025 (1) idem, jul 1987; FURG 87.0026 (1) Taím, Lagoa Mirim, 27 out 1987; FURG 87.0032 (1) Ponta Santiago, Lagoa Mirim, 19 jul 1987; FURG 87.0033 (1) Lagoa Mirim, 20 out 1987; FURG 87.0034 (3) Lagoa Mangueira, jul 1987; FURG 87.0036 (1) idem, ago 1987; FURG 87.0065 (3) ibidem, jul 1987; FURG 88.0002 (48) Taim, Lagoa Mirim, 29 dez 1988; FURG 90.0003 (1) Lagoa Man-

Revta bras. Zool. 19 (1): 251 - 287, 2002 


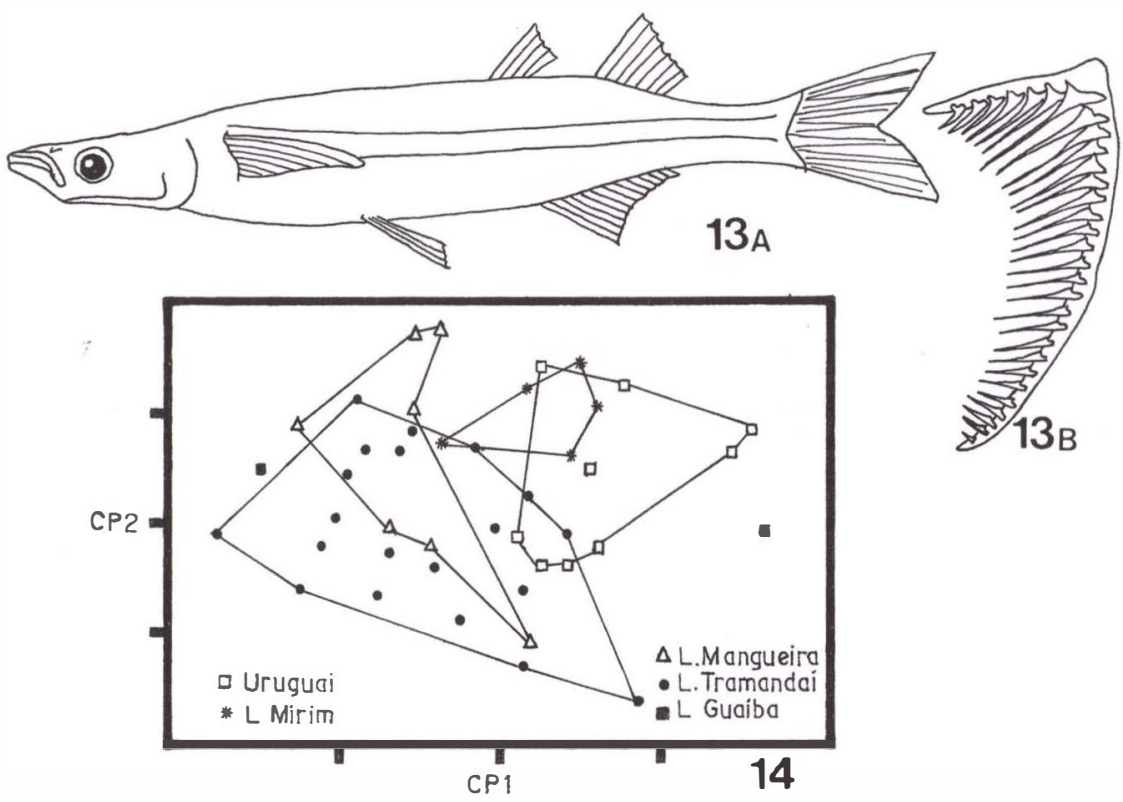

Figs 13-14. Odontesthes perugiae. (13) Exemplar de $180 \mathrm{~mm}$ de comprimento padrāo (A) FURG 87.0021 Lagoa Mangueira, Rio Grande do Sul, outubro de 1987, (B) primeiro arco branquial esquerdo; (14) projeção dos escores individuais de 44 exemplares, no espaço dos dois primeiros componentes principais (CP1, CP2), para 25 caracteres morfométricos; dados ajustados com projeçōes ortogonais de Bumaby.

gueira, jul 1990; FURG 92.0007 (16) Lagoa Fortaleza, 16 jun 1992; MCP 6893 (1) Rio Guaíba, 29 jan 1985; MCN 7089 (1) Parque Estadual do Jacuí, s/data; UFRGS s/n (21) Lagoa Emboaba, ago 1985. URUGUAI: INAPE 258 (1) Embalse del Rio Negro, Durazno ago 1972; INAPE s/n (5) idem set 1991. ARGENTINA: MLP 1.3.41.25 (3) Rio Uruguai, Província de Entre Rios, 1 mar 1941; MLP 8.7.60.27 (9) Parque Belgrano, Santa Fé, 8 jul 1960.

Diagnose. Odontesthes aff. perugiae distingue-se das demais espécies da região sul pela presença de 30 a 37 rastros no primeiro arco branquial, sobrepondo-se com $O$. argentinensis (27 a 33) e O. mirinensis (31 a 37). Difere destas, pelo focinho longo, 8,2 a 10,7\% do comprimento padrão, contra 6 a $8 \%$ em $O$. argentinensis e $O$. mirinensis; dentes vomerianos arranjados em três placas conectadas; cleitrum sem escamas; duas séries de escamas sub-oculares.

Descrição. O comprimento padrão dos exemplares examinados variou de 113 a $267 \mathrm{~mm}$. As relações morfométricas e merísticas encontram-se na tabela XI. Corpo alongado de pouca altura, recoberto com escamas de bordo posterior liso; duas séries de escamas sub-oculares, ausente no focinho; cleitrum sem 
Tabela XI. Dados comparativos dos caracteres morfométricos e merísticos de quatro populaçōes de 0 . perugiae; (Tramandai = lagoas Emboada e Fortaleza; Uruguai = rios Negro e Uruguai). Medidas expressas em percentagens do comprimento padrāo e comprimento da cabeça; (cv) coeficiente de variação.

\begin{tabular}{|c|c|c|c|c|c|c|c|c|c|c|c|c|c|c|c|c|c|c|c|c|}
\hline \multirow{2}{*}{ Variáveis } & \multicolumn{5}{|c|}{ Lagoa Mangueira $(n=7)$} & \multicolumn{5}{|c|}{ Tramandai $(n=21)$} & \multicolumn{5}{|c|}{ Lagoa Mirim ( $n=5)$} & \multicolumn{5}{|c|}{ Uruguai $(n=9)$} \\
\hline & Min & Máx & Méd & Des & $\mathrm{cv}$ & Min & Máx & Méd & Des & $\mathrm{cr}$ & Min & Máx & Méd & Des & $\mathrm{cv}$ & in & Máx & Méd & Des & cv \\
\hline $\mathrm{cp}(\mathrm{mm})$ & 175 & 213 & & & & 113 & 177 & & & & 145 & 267 & & & & 120 & 185 & & & \\
\hline \multicolumn{21}{|c|}{$\begin{array}{l}\text { Percentagem do comprimento } \\
\text { padrāo }\end{array}$} \\
\hline pd1 & 61,7 & 64,0 & 63,1 & 0,87 & 1,38 & 60,6 & 67,3 & 63 & 2,34 & 3,67 & 61,8 & 65,5 & 63,1 & 1,28 & 2,03 & 62,5 & 65,9 & 63,7 & 1,13 & 1,77 \\
\hline pd2 & 7 & 7 & & 0,8 & 1,05 & 73,5 & 81 & & 2, & 3,07 & 75,6 & 7 & & 8 & 0,76 & 75,0 & & 3 & 1,63 & 2,11 \\
\hline pan & 64,3 & 67,7 & 66,6 & 1,22 & 1,84 & 64,8 & 71,9 & 68,6 & 2,13 & 3,11 & 68,2 & 70,8 & 69,3 & 0,95 & 1,37 & 65,8 & 71,4 & 68,3 & 2,06 & 3,07 \\
\hline pp1 & 2 & 2 & 2 & 1,36 & 5,11 & 24,3 & 30,0 & 27 & 1,41 & 5,13 & 25,1 & & 3 & 0,74 & 2,81 & 25,0 & 2 & 4 & 1,24 & 4,71 \\
\hline pp2 & 45,5 & 50,0 & 5 & 1 & 3,18 & 45,3 & 52,1 & & 1 & 4,31 & 49,1 & 5 & 3 & 0,86 & 1,70 & 45,6 & 50,4 & 7 & 1,55 & 3,25 \\
\hline$c a b$ & 2 & 27 & & & 4,40 & 21,5 & 27,6 & & 1 & 7,10 & 23,1 & 2 & & 4 & 3,05 & 22,9 & 2 & & 0,86 & 3 \\
\hline altcab & 11,4 & 13,8 & 13,0 & 0. & 5,76 & 11,2 & 12,7 & 12,0 & 0,48 & 3,98 & 11,6 & 12,4 & 12,2 & 0,29 & 2,41 & 10,1 & 14,1 & 11,6 & 1,03 & 8,89 \\
\hline foc & & 10,6 & & & 8,32 & 8,4 & 10,7 & 9,3 & 7 & 7,16 & 7 & 4 & 0 & 25 & 2 & 2 & 7 & 3 & 0,46 & 5,23 \\
\hline altped & 7,4 & 8,0 & 7,6 & 0,20 & 2,61 & 7,1 & 9,0 & 8,1 & 0,51 & 6,29 & 7,0 & 8,1 & 7,3 & 0,44 & 6,00 & 7,0 & 8,2 & 7,6 & 0,41 & 5,38 \\
\hline p1p2 & 20,8 & 25,8 & & 1 & 6,22 & 21,5 & 24,8 & 23,1 & 1,01 & 4,40 & 25,6 & 26,8 & 26,1 & 2 & 1. & 22,0 & 2 & 23 & 1,0 & 4,4 \\
\hline pipc & 7 & 76,8 & 7 & 0,94 & 1,25 & 73,4 & 81,5 & 7 & 5 & 3,00 & 74,8 & 76,8 & 7 & 0,69 & 0,91 & 73,4 & 78 & م & 1,44 & 1,89 \\
\hline p2pc & & 5 & & 1 & 1,83 & 55,0 & & & 3 & 3 & 8 & 5 & 5 & 79 & 1. & 5 & & ) & 1 & 3 \\
\hline anpc & 33,9 & 36,6 & 3 & 0,98 & 2,75 & 33,8 & 40,6 & 37,7 & 1,81 & 4,80 & 34,0 & , & 4 & 0,44 & 1,28 & 34,2 & 3 & 3 & 1,14 & 3 , \\
\hline d1pc & 3 & 3 & 2 & 0, & 2,11 & 35,2 & 43 & 4 & 5 & 4,82 & 9 & & & & 3 & 5,7 & 4 & & 1 & 4 \\
\hline d2pc & 24,2 & 26,1 & 2 & 0,71 & 2,79 & 23,5 & 28,6 & 26,5 & 1,51 & 5,70 & 23,7 & 25,2 & 24,6 & 0,53 & 2,15 & 22,8 & 27,5 & 24,6 & 1,53 & 6,22 \\
\hline d1d2 & 7 & 14,8 & 1 & 1. & 8,30 & 12,1 & 15,8 & 13,9 & 1,16 & 8,33 & 11,7 & 13,9 & 12,5 & 0,83 & 6,66 & 11,1 & 1 & 13,3 & 1,01 & 7,6 \\
\hline and1 & 2 & 18,9 & & 0,79 & 4,52 & 15,3 & 20,1 & & 1,05 & 6,15 & 16,0 & 17,9 & 16,8 & 0,72 & 4,31 & 14,3 & 16,8 & 15,8 & 0,78 & 4,9 \\
\hline and2 & 1 & 20,6 & 1 & 0,52 & 2,64 & 17,6 & 21,1 & 19,4 & 1,02 & 5,26 & 17,0 & 20,0 & 18,2 & 1,11 & 6,08 & 16,2 & 19,5 & 18,3 & 0,99 & 5,42 \\
\hline anp1 & 3 & & & 1,89 & 4,48 & 39,0 & 44,5 & 42,2 & 1,54 & 3,64 & 44,0 & 46,4 & & 0,81 & 1,79 & 40,2 & & 43,0 & 1,49 & 3. \\
\hline anp2 & 17,8 & 22,5 & 20,3 & 1,28 & 6,32 & 18,1 & 23,0 & 2 & 1,40 & 6,85 & 2 & 2 & 2 & 55 & 3,07 & 19,6 & 22 & 3 & 1,12 & 5,2 \\
\hline \multicolumn{21}{|c|}{ Percentagem do comprimento da cabeça } \\
\hline foc & 34,3 & 38,6 & 35,6 & 1,39 & 3,90 & 34,5 & 41,9 & 3 & 2,27 & 5,86 & 36,0 & 40,7 & 3 & & 4,67 & 34,0 & 39 & 35,9 & 1,41 & 3,9 \\
\hline olho & & 20 & & & 5,61 & 17,5 & 23 & & 1,72 & 8,22 & 15,9 & & & & 7,86 & 16,1 & 21,4 & 17,9 & 1,851 & 10, \\
\hline interorb & 23,5 & 28,6 & 26,1 & 1,50 & 5,76 & 24,8 & 31,6 & 27,7 & 2,28 & 8,21 & 25,9 & 28,6 & 27,6 & 1,00 & 3,61 & 22,8 & 27,6 & 25,2 & 1,55 & 6,14 \\
\hline boca & 4 & & & & 5,74 & 20,2 & & & 1,49 & 6,40 & 25,0 & 8 & 6 & 3 & 3,49 & 23,0 & 6 & 25,0 & 1,84 & 7,34 \\
\hline $\max$ & 3 & 37,3 & 35 & 1,20 & 3,40 & 32,3 & 39,1 & 3 & 1,83 & 4,94 & 35,6 & 38,1 & 36,5 & 0,88 & 2,42 & 33,2 & 38,3 & 35,8 & 1,65 & $4, \epsilon$ \\
\hline \multicolumn{21}{|l|}{ Contagens } \\
\hline d1 & 4 & 5 & 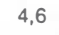 & 0,5 & 10,8 & 4 & 5 & 4,4 & 0,5 & 11 , & 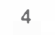 & 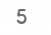 & 7,7 & 0,5 & & 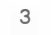 & 5 & 4,3 & 0,7 & 15,4 \\
\hline d2 & 8 & 10 & 8,9 & 0,6 & 7,2 & 8 & 10 & 8,6 & 0,7 & 8,1 & 8 & 10 & 8,6 & 0,8 & 9,3 & 8 & 9 & 8,7 & 0,5 & 5,4 \\
\hline an & 16 & 17 & 16,7 & 0,5 & 2,7 & 15 & 17 & 16,3 & 0,8 & 4,7 & 15 & 16 & 15,4 & 0,5 & 3,2 & 14 & 17 & 15,6 & 0,8 & 5,3 \\
\hline and2 & 9 & 11 & 9,9 & 0,8 & 8,5 & 9 & 11 & 9,8 & 0,8 & 7,7 & 9 & 9 & 9,0 & 0,0 & 0,0 & 9 & 12 & 9,8 & 1,0 & 10,5 \\
\hline p1 & 13 & 13 & 13,0 & 0,0 & 0,0 & & & & & & 13 & 13 & 13,0 & 0,0 & 0,0 & 12 & 12 & 12,0 & 0,0 & 0,0 \\
\hline eslong & 47 & 50 & 48,4 & 0,9 & 1,9 & 46 & 50 & 48,4 & 0,9 & 1,9 & 46 & 49 & 48,0 & 1,1 & 2,3 & 48 & 51 & 49,7 & 0,9 & 1,9 \\
\hline espd1 1 & 20 & 22 & 20,7 & 0,9 & 4,3 & 20 & 22 & 20,8 & 0,5 & 2,5 & 20 & 22 & 21,0 & 0,6 & 3,0 & 21 & 25 & 22,3 & 1.5 & 6,6 \\
\hline esped & 14 & 16 & 14.6 & 0,9 & 6,2 & 14 & 14 & 14,0 & 0,0 & 0,0 & 14 & 16 & 15,2 & 1,0 & 6,4 & 16 & 16 & 16,0 & 0,0 & 0,0 \\
\hline bras & 6 & 8 & 7,1 & 0,6 & 8,9 & 6 & 7 & 6,6 & 0,5 & 7,6 & 7 & 8 & 7,4 & 0,5 & 6,6 & 5 & 8 & 6,0 & 1,1 & 17,6 \\
\hline brai & 27 & 30 & 28,7 & 0,9 & 3,1 & 26 & 29 & 27,8 & 0,9 & 3,2 & 26 & 29 & 27,8 & 1,2 & 4,2 & 24 & 29 & 26,3 & 2,0 & 7,6 \\
\hline brat & 33 & 37 & 35,9 & 1,4 & 3,8 & 32 & 36 & 34,4 & 1,1 & 3,1 & 33 & 37 & 35,2 & 1,6 & 4,5 & 30 & 36 & 32,3 & 2,3 & 7,0 \\
\hline
\end{tabular}

escamas no bordo. Cabeça muito proeminente 22,9 a 27,6\% do comprimento padrão (cp); altura da cabeça 10,1 a 14,1\% do cp. Focinho saliente 34 a 41,9\% do comprimento da cabeça (cab); olhos medianos 15,9 a 23,7\% da cab; boca muito protrátil com largura entre 20,2 e $28,6 \%$ da cab; maxila sobressai anteriormente à mandíbula; parte posterior da maxila chega até a borda do olho; dentes mandi-bulares cônicos e aciculares, em forma de gancho, dispostos em duas séries; dentes vomerianos arranjados em três placas; endopterigóides com placas 
de dentes reduzidos. Origem da primeira dorsal em cima do ânus ou posterior a ele; segunda dorsal origina-se sobre a vertical que passa entre o $9^{\circ}$ e $11^{\circ}$ raios da nadadeira anal. Extremidade distal das peitorais, apoiadas à superfície do corpo, não alcança a origem das pélvicas, faltando cerca de duas escamas; presença de membrana inter-pélvica em alguns dos exemplares examinados. Dorsal III a V e 8 a 10 raios; anal 14 a 17 raios: linha longitudinal com 46 a 51 séries de escamas, sendo 20 a 25 anteriores à primeira dorsal (espd1). Rastros do primeiro arco branquial com 5 a 8 no ramo superior, 24 a 30 no inferior, totalizando 30 a 37 (Fig. 13B). Vértebras: 25 pré-caudais, 22 a 23 caudais, totalizando de 47 a 48 ; as primeiras oito vértebras caudais tem o arco hemal expandido formando um funil hemal (urosoma) por onde se prolonga a bexiga natatória, até a metade da nadadeira anal.

Distribuição geográfica. Odontesthes aff. perugiae é uma espécie restrita a lagoas e rios. Sua ocorrência para o sul foi registrada até Rio de La Plata e delta do Rio Paraná, Argentina (MARRERo 1950). Foram examinados exemplares desde os rios Uruguai e Negro, no Uruguai até o Rio Jacuí, lagoas Emboaba e Fortaleza, ao norte do Estado do Rio Grande do Sul, Brasil (Fig. 1).

Variação intra-específica. A análise dos componentes principais foi realizada com sete exemplares da Lagoa Mangueira, cinco da Lagoa Mirim, 21 de lagoas junto à Tramandaí (Fortaleza e Emboaba), nove de rios do Uruguai (Negro e Uruguai) e dois do rio Guaiba. O primeiro componente principal (cpl), explicou $93,1 \%$ da variação total com coeficientes positivos e de semelhante magnitude (Tab. XII). Os coeficientes alométricos multivariados, indicaram que o caráter olho $(\alpha=0,55)$, juntamente com altura do pedúnculo e distâncias das nadadeiras ao pedúnculo caudal ( $\mathrm{p} 2 \mathrm{pc}$, anpc, $\mathrm{d} 1 \mathrm{pc}, \mathrm{d} 2 \mathrm{pc}$ ), tem alometria negativa, crescendo mais lentamente que o restante do corpo. Enquanto, boca, maxila, altura da cabeça, cabeça, distância pré-pélvica (pp2) e distância entre nadadeiras (plp2), tem alometrias positivas, crescendo mais rapidamente que o restante do corpo (Tab. XII).

No conjunto de dados ajustados pelas projeções ortogonais, os dois primeiros eixos representaram $20,5 \%$ e $16,9 \%$, respectivamente da variância total, com coeficientes positivos e negativos, indicando aspectos da forma do corpo. No diagrama de dispersão dos pontos, observou-se pequena discriminação entre dois grupos, um deles aproximou exemplares de "Tramandai-Mangueira" e o outro de "Mirim-Uruguai" (Fig. 14). Observou-se uma afinidade entre os exemplares da Lagoa Mangueira com Tramandai e Lagoa Mirim com rios do Uruguai. Os grupos mais independentes em termos de forma do corpo, foram os da Lagoa Mangueira e do Uruguai. Os caracteres que melhor determinaram a formação dos grupos, localizaram-se na região anterior do corpo (boca, cab e max, com coeficientes positivos) e na região mediana (and 1 , and 2 , $\mathrm{dl} d 2$, com coeficientes negativos) tabela XII. Observando-se porém, as proporções corporais médias dos espécimens analisados (Tab. XI), verificou-se não há variação na relação cabeça e região posterior do peixe, conforme o contraste de variáveis apresentado, portanto a diferenciação geográfica, baseada na forma do corpo dos exemplares examinados, ainda é um fato recente. 
Tabela XII. Análise dos componentes principais para O. perugiae (7 exemplares de rios do Uruguai, 7 Lagoa Mangueira, 21 lagoas de Tramandaí, 5 Lagoa Mirim, 2 Rio Guaiba); matriz de variância-covariância total para 25 caracteres morfométricos transformados em logaritmos; (cp 1) primeiro eixo extraído dos dados nāo ajustados; $(\alpha)$ coeficiente alométrico; coeficientes CP1 e CP2 obtidos com dados ajustados por projeçōes ortogonais.

\begin{tabular}{lcccc}
\hline \multicolumn{1}{c}{ Variáveis } & $\mathrm{cp} 1$ & $\alpha$ & $\mathrm{CP} 1$ & $\mathrm{CP} 2$ \\
\hline $\mathrm{cp}$ & 0,206 & 1,04 & 0,030 & 0,079 \\
$\mathrm{pd2}$ & 0,202 & 1,02 & $-0,002$ & 0,024 \\
$\mathrm{pc1}$ & 0,201 & 1,01 & 0,083 & 0,055 \\
$\mathrm{pan}$ & 0,204 & 1,03 & 0,112 & 0,027 \\
$\mathrm{pp2}$ & 0,210 & 1,06 & 0,062 & 0,021 \\
$\mathrm{pp1}$ & 0,207 & 1,04 & 0,088 & $-0,268$ \\
cab & 0,218 & 1,10 & 0,300 & $-0,166$ \\
altcab & 0,221 & 1,11 &,- 113 & 0,262 \\
foc & 0,208 & 1,05 & 0,149 & $-0,400$ \\
olho & 0,110 & 0,55 & $-0,261$ & $-0,028$ \\
interorb & 0,205 & 1,03 & $-0,109$ & $-0,160$ \\
boca & 0,237 & 1,19 & 0,401 & 0,202 \\
max & 0,211 & 1,06 & 0,232 & $-0,393$ \\
altped & 0,160 & 0,81 & $-0,175$ & 0,072 \\
p1p2 & 0,228 & 1,15 & 0,052 & 0,390 \\
p1pc & 0,96 & $-0,039$ & 0,077 \\
p2pc & 0,190 & $-0,047$ & 0,004 \\
anpc & 0,94 & $-0,113$ & $-0,068$ \\
d1pc & 0,187 & $-0,186$ & $-0,128$ \\
d2pc & 0,180 & 0,91 & $-0,160$ & $-0,038$ \\
d1d2 & 0,187 & 0,94 & $-0,354$ & 0,168 \\
and1 & 0,187 & 0,96 & $-0,381$ & 0,102 \\
and2 & 0,190 & 1,05 & 0,296 & 0,293 \\
anp1 & 0,208 & 0,937 & 0,113 \\
anp2 & 0,192 & 1,05 & 0,249 & 16,900 \\
\hline Variância (\%) & 0,209 & 1,04 & 20,500 & \\
\hline
\end{tabular}

\section{Odontesthes retropinnis (De Buen, 1953), comb.n.}

Fig. 15A, Tab. XIII

Yaci retropinnis De Buen, 1953: 52 (localidade-tipo: Embalse del Rio Negro, Uruguay).

Material examinado. Holótipo de Yaci retropinnis MHNM 1809 (134 mm cp) Embalse del Rio Negro (Arroyo Chileno) Durazno, Uruguay, 17 jul 1947.

Outros espécimens examinados. BRASIL, Rio Grande do Sul: FURG 87.0005 (3) Lagoa Mangueira, Rio Grande ago 1987; FURG 87.0037 (1) idem jul 1987; FURG 87.0038 (1) Ponta Santiago, Lagoa Mirim 19 jul 1987; FURG 87.0039 (1) Lagoa Mirim 20 out 1987; FURG 88.0006 (1) Lagoa Mangueira 4 ago 1988; MCN 8219 (1) Lagoa Mangueira, Santa Vitória do Palmar (sem data). ARGENTINA: MLP 10.1.50.12 (7) Lagoa Magdalena, Buenos Aires 10 jan 1950.

Diagnose. Odontesthes retropinnis distingue-se das demais espécies capturadas no sul do Brasil, pela presença de elevado número de rastros no primeiro arco branquial (56 a 63), as demais espécies possuem menos de 47; coloração "in vivo" amarelo-esverdeada no dorso, na membrana das nadadeiras e interior da órbita, as demais espécies são de cor branco-leitoso; arcos hemais expandidos formando um tubo hemal incompleto, cujas paredes delgadas são mais estreitas do que as demais espécies.

Revta bras. Zool. 19 (1): $251-$ 287, 2002 

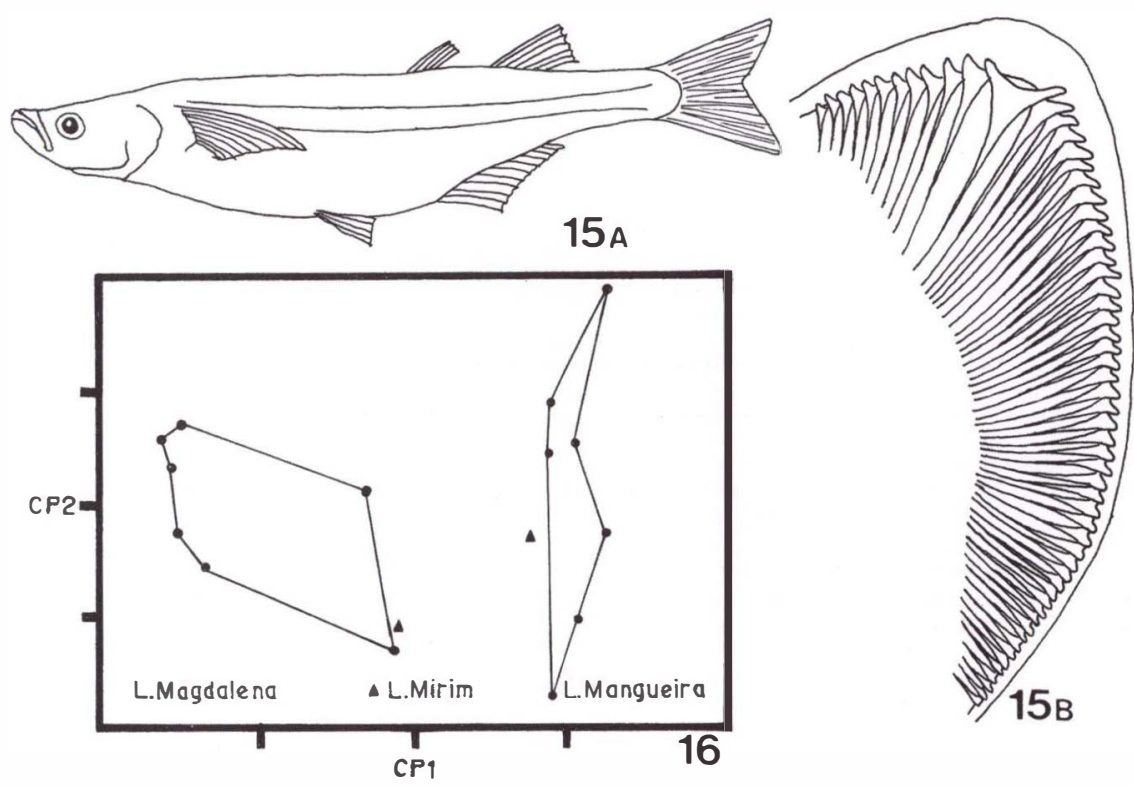

Figs 15-16. Odontesthes retropinnis. (15) Exemplar de $210 \mathrm{~mm}$ de comprimento padrāo (A), FURG 88.0006, Lagoa Mangueira, Rio Grande do Sul, 4 de agosto de 1988, (B) primeiro arco branquial esquerdo; (16) projeçāo dos escores individuais de 16 exemplares de $O$. retropinnis, no espaço dos dois primeiros componentes principais (CP1, CP2), para 25 caracteres morfométricos; dados nāo ajustados.

Descrição. O comprimento padrão dos exemplares examinados variou de 75 a $261 \mathrm{~mm}$. As relações morfométricas e merísticas encontram-se na tabela XIII. Corpo alto, mais largo que as demais espécies; ventre em curva pronunciada, estendendo-se desde a mandíbula até a nadadeira anal; escamas do corpo com bordo posterior liso; duas séries de escamas sub-oculares; cleitrum sem escamas no bordo. Cabeça 24,2 a 27\% do comprimento padrão (cp); altura da cabeça 13 a 16,5\% do cp. Focinho curto 27,4 a 35,8\% do comprimento da cabeça (cab); olho 14,2 a 27\% da cab; distância inter-orbital 23,8 a 33,3\% da cab; boca larga 25 a 30\% da cab. Maxila e mandíbula com mesma projeção anterior; fenda bucal inicia reta, inclinando-se para baixo; dentes mandibulares muito pequenos; poucos dentes no endopterigóide; vômer sem dentes. Origem da primeira dorsal sobre o ânus ou posterior a ele; segunda dorsal começa na vertical entre $8^{\circ}$ e $11^{\circ}$ raio da nadadeira anal; extremidade distal das nadadeiras peitorais, apoiadas à superfície do corpo, chega à origem das pélvicas ou passa pouco; pélvicas bem separadas; membrana inter-pélvica ausente. Dorsal IV a V e 8 a 10 raios; anal 16 a 17; linha longitudinal com 46 a 50 séries de escamas, sendo 20 a 24 anteriores à primeira dorsal. Rastros do primeiro arco branquial finos, longos, numerosos 10 a 13 no ramo superior, 46 a 50 no inferior, totalizando 56 a 63 (Fig. 15B). Vértebras: 26 pré-caudais, 21 a 22

Revta bras. Zool. 19 (1): 251 - 287 2nก? 
caudais, totalizando 47 a 48; as primeiras vértebras caudais (cerca de 10), apresentam o arco hemal expandido formando um funil hemal por onde se prolonga a bexiga natatória. O funil hemal tem as paredes laterais mais estreitas e delgadas mantendo os arcos hemais separados um do outro.

Tabela XIII. Dados comparativos dos caracteres morfométricos e merísticos de três populaçōes de $O$. retropinnis. Medidas expressas em percentagens do comprimento padrāo e comprimento da cabeça; (cv) coeficiente de variaçāo.

\begin{tabular}{|c|c|c|c|c|c|c|c|c|c|c|c|c|c|c|c|}
\hline \multirow{2}{*}{ Variáveis } & \multicolumn{5}{|c|}{ Lagoa Mangueira $(n=7)$} & \multicolumn{5}{|c|}{ Lagoa Mirim $(n=2)$} & \multicolumn{5}{|c|}{ Lagoa Magdalena $(n=7)$} \\
\hline & Min & Máx & Méd & Des & cv & Min & Máx & Méd & Des & cv & Min & Máx & Méd & Des & $\mathrm{cv}$ \\
\hline $\mathrm{cp}(\mathrm{mm})$ & 210 & 261 & & & & 165 & 240 & & & & 73,6 & 140 & & & \\
\hline \multicolumn{16}{|c|}{ Percentagem do comprimento padrāo } \\
\hline pd1 & 60,8 & 64,7 & 62,0 & 1,25 & 2,01 & 62,1 & 63,5 & 62,8 & 0,70 & 1,12 & 60,7 & 62,6 & 61,6 & 0,73 & 1,19 \\
\hline pd2 & 70,7 & 75,7 & 73,2 & 1,35 & 1,85 & 71,4 & 74,9 & 73,2 & 1,72 & 2,36 & 71,3 & 73,1 & 71,8 & 0,56 & 0,78 \\
\hline pan & 62,5 & 67,6 & 65,6 & 1,63 & 2,48 & 65,7 & 67,0 & 66,4 & 0,64 & 1,97 & 63,0 & 67,5 & 65,0 & 1,36 & 2,09 \\
\hline pp1 & 26,5 & 28,7 & 27,6 & 0,76 & 2,74 & 27,1 & 28,1 & 27,6 & 0,47 & 1,69 & 25,3 & 27,3 & 26,3 & 0,74 & 2,82 \\
\hline pp2 & 45,9 & 50,5 & 48,6 & 1,62 & 3,33 & 48,6 & 49,3 & 48,9 & 0,34 & 0,70 & 45,7 & 48,0 & 46,6 & 0,86 & 1,85 \\
\hline cab & 24,9 & 27,0 & 25,8 & 0,63 & 2,46 & 26,1 & 26,6 & 26,3 & 0,26 & 1,00 & 24,2 & 25,7 & 24,8 & 0,51 & 2,07 \\
\hline altcab & 13,8 & 16,5 & 15,3 & 0,78 & 5,17 & 13,8 & 14,3 & 14,0 & 0,25 & 1,75 & 13,0 & 15,3 & 13,9 & 0,80 & 5,75 \\
\hline foc & 7,9 & 9,2 & 8,7 & 0,36 & 4,19 & 8,6 & 8,9 & 8,7 & 0,15 & 1,69 & 6,7 & 8,5 & 7,4 & 0,60 & 8,08 \\
\hline altped & 6,9 & 8,0 & 7,7 & 0,35 & 4,51 & 7,9 & 7.9 & 7,9 & 0,01 & 0,16 & 7,2 & 8,6 & 8,0 & 0,46 & 5,74 \\
\hline p1p2 & 22,5 & 26,1 & 24,6 & 1,22 & 4,95 & 22,9 & 24,1 & 23,5 & 0,64 & 2,72 & 20,5 & 23,1 & 22,1 & 0,80 & 3,62 \\
\hline p1pc & 72,9 & 76,4 & 75,3 & 1,20 & 1,59 & 74,9 & 75,0 & 74,9 & 0,06 & 0,08 & 73,1 & 76,4 & 75,2 & 1,00 & 1,33 \\
\hline p2pc & 56,3 & 61,9 & 58,7 & 1,95 & 3,33 & 57,1 & 58,1 & 57,6 & 0,49 & 0,85 & 57,2 & 59,5 & 58,0 & 0,77 & 1,32 \\
\hline anpc & 36,8 & 42,8 & 39,7 & 2,55 & 6,43 & 37,4 & 37,9 & 37,6 & 0,21 & 0,56 & 38,5 & 42,3 & 40,3 & 1,18 & 2,93 \\
\hline d1pc & 37,6 & 41,4 & 39,1 & 1,09 & 2,78 & 36,9 & 37,1 & 37,0 & 0,10 & 0,27 & 37,9 & 41,2 & 39,3 & 1,17 & 2,99 \\
\hline d2pc & 27,4 & 30,4 & 28,8 & 1,33 & 4,65 & 26,1 & 27,9 & 27,0 & 0.87 & 3,24 & 27,6 & 30,7 & 29,0 & 1,13 & 3,91 \\
\hline d1d2 & 9,6 & 12,3 & 11,2 & 0,94 & 8,37 & 10,4 & 11,3 & 10,8 & 0,49 & 4,49 & 9,5 & 11,8 & 10,6 & 0,75 & 7,12 \\
\hline and1 & 16,9 & 19,5 & 18,4 & 0,85 & 4,59 & 17,9 & 19,2 & 18,5 & 0,67 & 3,65 & 17,1 & 19,2 & 18,2 & 0,66 & 3,60 \\
\hline and2 & 18,8 & 22,0 & 20,8 & 0,92 & 4,44 & 20,0 & 22,2 & 21,1 & 1.08 & 5,14 & 19,3 & 21,9 & 20,6 & 0,83 & 4,03 \\
\hline anp1 & 37,6 & 43,6 & 41,2 & 2.18 & 5,30 & 39,9 & 40,7 & 40,3 & 0,41 & 1,01 & 38,0 & 41,1 & 39,4 & 1,24 & 3,14 \\
\hline anp2 & 16,9 & 23,1 & 19,7 & 1,89 & 9,59 & 22,2 & 23,6 & 22,9 & 0,70 & 3,07 & 17,1 & 20,9 & 19,2 & 1,28 & 6,65 \\
\hline \multicolumn{16}{|c|}{ Percentagem do comprimento da cabeça } \\
\hline foc & 31,7 & 35,8 & 33,8 & 1,32 & 3,91 & 32,9 & 33,3 & 33,1 & 0,23 & 0,69 & 27,4 & 34,3 & 30,1 & 2,42 & 8,07 \\
\hline olho & 14,2 & 17,7 & 15,3 & 1,14 & 7,44 & 14,8 & 19,2 & 17,0 & 2,18 & 12,84 & 21,4 & 27,0 & 24,2 & 1,99 & 8,25 \\
\hline interorb & 28,4 & 33,3 & 31,9 & 1,59 & 5,00 & 30,1 & 31,5 & 30,8 & 0,67 & 2,18 & 23,8 & 33,2 & 27,3 & 2,95 & 10,80 \\
\hline boca & 25,0 & 30,2 & 28,2 & 1,98 & 7,00 & 27,4 & 27,8 & 27,6 & 0,19 & 0,69 & 26,2 & 29,4 & 27,7 & 1,15 & 4,17 \\
\hline $\max$ & 30,6 & 35,8 & 33,8 & 1,58 & 4,67 & 32,9 & 33,3 & 33,1 & 0,23 & 0,69 & 31,1 & 36,4 & 34,0 & 1,86 & 5,46 \\
\hline \multicolumn{16}{|l|}{ Contagens } \\
\hline d1 & 4 & 5 & 4,1 & 0,3 & 8.4 & 4 & 4 & 4,0 & 0,0 & 0,0 & 4 & 4 & 4,0 & 0,0 & 0,0 \\
\hline d2 & 8 & 9 & 8,9 & 0,3 & 4,0 & 8 & 9 & 8,5 & 0,5 & 5,9 & 9 & 10 & 9,7 & 0.5 & 4,9 \\
\hline an & 16 & 17 & 16,9 & 0,3 & 2,1 & 16 & 17 & 16,5 & 0,5 & 3,0 & 17 & 17 & 17,0 & 0,0 & 0,0 \\
\hline and2 & 8 & 10 & 9,0 & 0,8 & 8,4 & 10 & 10 & 10,0 & 0,0 & 0,0 & 10 & 11 & 10.3 & 0,5 & 4,6 \\
\hline p1 & 12 & 13 & 12,7 & 0,5 & 3,6 & 13 & 13 & 13,0 & 0,0 & 0,0 & 13 & 13 & 13,0 & 0,0 & 0.0 \\
\hline eslong & 46 & 50 & 48,3 & 1,6 & 3,3 & 48 & 49 & 48,5 & 0,5 & 1,0 & 47 & 50 & 48,0 & 1,4 & 2,9 \\
\hline espd1 & 20 & 24 & 21,9 & 1,4 & 6,2 & 22 & 22 & 22,0 & 0,0 & 0,0 & 20 & 22 & 21.0 & 1,0 & 4,8 \\
\hline esped & 16 & 16 & 16,0 & 0,0 & 0,0 & 16 & 16 & 16,0 & 0,0 & 0,0 & 16 & 16 & 16,0 & 0,0 & 0,0 \\
\hline bras & 10 & 13 & 11,4 & 0,9 & 7,9 & 11 & 11 & 11,0 & 0,0 & 0,0 & 12 & 13 & 12,7 & 0,5 & 3,7 \\
\hline brai & 46 & 50 & 47,4 & 1,3 & 2,7 & 46 & 47 & 46,5 & 0,5 & 1,1 & 48 & 50 & 49,3 & 0,9 & 1,9 \\
\hline brat & 57 & 63 & 58,9 & 2,0 & 3,3 & 57 & 58 & 57,5 & 0,5 & 0,9 & 61 & 63 & 62,0 & 0,8 & 1,3 \\
\hline
\end{tabular}

Comentários. Odontesthes retropinnis foi descrita no gênero Yaci De Buen, 1953 em base a ausência de expansões laterais dos arcos hemais, também observado em $O$. incisa. Neste trabalho, a espécie foi considerada como parte do gênero Odontesthes, uma vez que seus caracteres são semelhantes àqueles propostos por WhITE (1985), na diagnose do gênero. PRODOHL \& LEVY (1989) em um estudo genético bioquímico dos peixes aterinídeos da Lagoa Mangueira, Rio Grande do 
Sul, determinaram que em função dos valores de identidade genética de Nei (INEI), $O$. retropinnis manteve-se no intervalo esperado para espécies congenéricas: INEI $=0,745 \mathrm{com} O$. argentinensis e INEI $=0,583 \mathrm{com} O$. humensis, onde diferentes gêneros tem valores que oscilam entre 0,0 e 0,3 .

Distribuição geográfica. Odontesthes retropinnis tem como registro de ocorrência, até o momento, sua localidade-tipo [Embalse del rio Negro, Uruguay DE BUEN (1953)]. Apesar de ter sido pouco abundante e de difícil captura, foi possível determinar o limite norte de sua ocorrência, nas Lagoas Mirim e Mangueira, Rio Grande do Sul, Brasil (Fig. 1) e ao sul até a Lagoa Magdalena, Província de Buenos Aires, Argentina.

Variação intra-específica. A análise dos componentes principais foi realizada com dois exemplares da Lagoa Mirim e sete da Lagoa Mangueira (Brasil), sete da Lagoa Magdalena (Argentina). Nesta análise o conjunto de dados não foi ajustado pelas projeções ortogonais, para interferência do tamanho, porque o número de indivíduos foi inferior ao número de variáveis morfométricas, uma exigência do programa. O diagrama de dispersão dos pontos indicou que houve pouca variação morfológica entre os peixes amostrados (Fig. 16). A distribuição foi influenciada pelo tamanho dos exemplares, os maiores (203 a $261 \mathrm{~mm} \mathrm{cp}$ ), estavam dispostos no lado direito do gráfico, enquanto os menores (73,6 a $82,0 \mathrm{~mm} \mathrm{cp}$ ), estavam no lado esquerdo. O primeiro componente principal explicou $99,2 \%$ da variação total, enquanto o segundo e terceiro componentes, apenas $0,23 \%$ e $0,13 \%$, respectivamente. Os coeficientes alométricos multivariados, indicaram que os caracteres olho $(\alpha=0,51) \mathrm{e}$ altura do pedúnculo $(\alpha=0,90)$, tem alometria negativa, crescendo mais lentamente que o restante do corpo. Enquanto, altura da cabeça, focinho, inter-orbital e distância

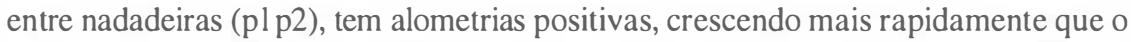
restante do corpo (Tab. XIV). Os demais caracteres mostraram-se isométricos. Houve variabilidade entre os caracteres dos indivíduos maiores e menores, registrada pelo coeficiente de variação, que apresentou baixo valor individual entre os grupos (Tab. XIII), e elevado valor quando os indivíduos foram reunidos, como foi o caso da variável olho (cv = 23,49). As proporções corporais diferiram largamente entre as populações, como resultado do fenômeno alométrico, influenciadas pelo baixo número de indivíduos $(n=16)$, não representando variação de forma entre os peixes.

Tabela XIV. Análise dos componentes principais para O. retropinnis (7 exemplares da Lagoa Mangueira, 2 da Lagoa Mirim, Brasil, 7 da Lagoa Magdalena, Argentina); matriz de variânciacovariância total para 25 caracteres morfométricos transformados em logaritmos; $(\alpha)$ coeficiente alométrico; coeficientes CP1 e CP2 obtidos com dados nāo ajustados.

\begin{tabular}{lccc}
\hline \multicolumn{1}{c}{ Variáveis } & $\mathrm{CP} 1$ & $\mathrm{CP} 2$ & $\alpha$ \\
\hline $\mathrm{cP}$ & 0,201 & 0,083 & 1,01 \\
$\mathrm{pd2}$ & 0,206 & 0,159 & 1,04 \\
$\mathrm{pc1}$ & 0,079 & 1,02 \\
$\mathrm{pan}$ & 0,202 & $-0,069$ & 1,02 \\
$\mathrm{pp2}$ & 0,203 & 0,012 & 1,05 \\
$\mathrm{pp1}$ & 0,208 & 0,151 & 1,05 \\
cab & 0,208 & 0,133 & 1,03 \\
altcab & 0,205 & $-0,002$ & 1,07
\end{tabular}

Cont. 
Tabela XIV. Continuaçāo.

\begin{tabular}{lccc}
\hline \multicolumn{1}{c}{ Variáveis } & CP1 & CP2 & $\alpha$ \\
\hline toc & 0,215 & 0,207 & 1,08 \\
olho & 0,102 & $-0,191$ & 0,51 \\
interorb & 0,225 & $-0,127$ & 1,13 \\
boca & 0,195 & $-0,037$ & 0,98 \\
max & 0,193 & $-0,021$ & 0,97 \\
altped & 0,180 & $-0,070$ & 0,90 \\
p1p2 & 0,217 & $-0,040$ & 1,09 \\
p1pc & 0,201 & $-0,008$ & 1,02 \\
p2pc & 0,204 & $-0,088$ & 1,03 \\
anpc & 0,195 & $-0,098$ & 0,98 \\
d1pc & 0,197 & 0,148 & 0,99 \\
d2pc & 0,195 & $-0,030$ & 0,98 \\
d1d2 & 0,594 & 1,00 \\
and1 & 0,199 & $-0,060$ & 0,99 \\
and2 & 0,197 & $-0,032$ & 1,00 \\
anp1 & 0,198 & $-0,169$ & 1,05 \\
anp2 & 0,209 & $-0,621$ & 1,02 \\
\hline Variância $(\%)$ & 0,202 & 0,230 & \\
\hline
\end{tabular}

\section{Chave de identificação para as espécies de Odontesthes do sul do Brasil}

1a. linha longitudinal com mais de 59 escamas (59-67); funil hemal ausente; cleithrum com escamas presentes no bordo; três séries de escamas suboculares; origem da primeira nadadeira dorsal anterior a origem da nadadeira

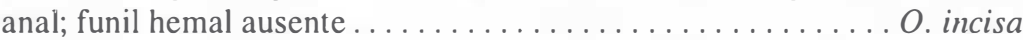

lb. linha longitudinal com menos de 59 escamas (46-59); funil hemal presente . . 2

2a. rastros branquiais mais que 40 , finos e longos . ................ 3

2b. rastros branquiais menos que $37 \ldots \ldots \ldots \ldots \ldots \ldots \ldots \ldots \ldots$

3a. rastros branquiais totais entre 56-63 (10-13 + 46-50); dentes vomerianos ausentes; cleithrum com ausência de escamas; focinho curto 6,5-9\% do cp.; origem a primeira nadadeira dorsal sobre o ânus ou posterior a ele; 2 séries de escamas sub-oculares .................. retropinnis

3b. rastros branquiais totais entre 40-47 (8-11 + 32-37); dentes vomerianos em um único grupo mediano; focinho proeminente $8-10 \%$ do cp.; origem a primeira nadadeira dorsal entre o final das pélvicas e o ânus; mandíbula prognata . .

O. bonariensis

4a. rastros branquiais totais entre 20-24 (4-6+15-19); dentes vomerianos ausentes; maxila proeminente dirigida para baixo; 2 séries de escamas sub-oculares; cleithrum com ausência de escamas; focinho curto $7-9 \%$ do cp . . . . . . . . .

O. humensis

4b. rastros branquiais totais entre 27-37; cleithrum com ausência de escamas (exceto

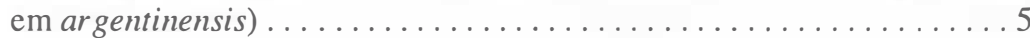

5a. cleithrum com escamas presentes no bordo; 3 ou 4 filas de escamas sub-oculares; escamas crenuladas na pré-dorsal; funil hemal bem desenvolvido; rastros branquiais inferiores 20-24 O. argentinensis 
5b. cleithrum com ausência de escamas no bordo; 2 filas de escamas sub-oculares; escamas lisas; rastros branquiais inferiores entre 23-29 (grupo de espécie: aff. perugiae - 23-30; 24-29 mirinensis) . . . . . . . . . . . . . . 6

6a. focinho curto 6-8\% do cp; ausência de dentes vomerianos; ramo inferior do préoperculo com 4 poros sensoriais . ........... mirinensis

6b. Focinho proeminente $8-11 \%$ do $\mathrm{cp}$; dentes vomerianos em 3 grupos; ramo inferior do préoperculo formando um canal aberto . . . . . . O. aff. perugiae

AGRADECIMENTOS. A CAPES pela bolsa de PICD. Ao CNPq e FAPERGS pelo auxílio de parte dos recursos necessánios ao desenvolvimento do trabalho. Ao Dr. Chossi Sinque pela orientação e apoio. Aos Drs. Sérgio F. dos Reis (UNICAMP), Roberto E. dos Reis (PUCRS), João P. Vieira (FURG), assim como Rubens A. da Cunha, pela leitura e críticas na revisão de partes deste trabalho. Aos Drs. Carlos Borzone (UFPR)e Tabajara Almeida (FURG) pelo auxílio na análise estatísticas. Aos colegas Denis Dolci, Angelo Maf fissoni, GermanoPhonlor, Guassenir Born (FURG), Paulo Roberto Moraes (UFPel) e Paulo A. Prodohl pelo auxílio nas coletas. Aos técnicos de laboratório Artur Oscar L. Dutra e Lucia Pacheco pelo acompanhamento nas coletas, biometria dos peixes e confeç̧ão de parte dos desenhos, respectivamente. A André Bruegger, Luciano Beheregaray, André Gonçalves e Luciano Fischer pela colaboração nas coletas, biometria, análise dos dados e auxílio em algumas ilustrações. Em especial ao Dr. Carlos Emilio Bemvenuti (FURG) pela compreensão na revisão final do texto. Às seguintes pessoas e instituiçōes pelo empréstimo e doações de exemplares: Brian Dyer (MZUM) pela cedência dos dados biométricos do material-tipo de Atherina argentinensis (MNHN A.4362 e A.4363) e A. bonariensis (MNHN A.4407); Luiz R. Malabarba (MCP e UFRGS); Leda A. Jardim (UFRGS); José Lima Figueiredo e Naércio Menezes (MZUSP); Mauricio Hostim da Silva (NEMAR, UFSC); India M.Borba (MNRJ- in memorian); Graciela Fabiano e Fernando Peluffo (INAPE, Uruguai); Héctor Osório (MHNM, Uruguai); Hugo Lopez e Mirta Garcia (MLP, Argentina).

\section{REFERÊNCIAS BIBLIOGRÁFICAS}

Bemvenuti, M.A. 1993. Redescrição do peixe-rei Odontesthes argentinensis (Valenciennes) Pisces: Atherinidae, na costa do Rio Grande do Sul. Atlântica, Rio Grande, 15: 17-35.

1995. Odontesthes mirinensis sp.n., um novo peixe-rei (Pisces, Atherinidae, Atherinopsinae) para o extremo sul do Brasil. Revta bras. Zool. 12 (4): 881-903.

-2000. Diferenciação geográfica do peixe-rei Odontesthes argentinensis (Atherinopsidae), no extremo sul do Brasil, através da morfometria multivariada. Atlântica, Rio Grande, 22: 71 -79.

Bookstein, F.; B. Chernoff; R. Elder; J. Humphries; G. Smith; R. Strauss. 1985. Morphometrics in evolutionary biology. Acad. Nat. Sci. Philad., Spec. Publ. (15): 1-277.

BURNABY, T.P. 1966. Growth-invariant discriminant functions and generalized distances. Biometrics 22: $96-110$.

Delaney, P.J.V. 1965. Fisiografia e geologia da superfície da Planície Costeira do Rio Grande do Sul. Public. Especial Escola de Geologia, Porto Alegre, 6: 1-195.

DE BUEN, F. 1953. Los pejerreyes (Familia Atherinidae) en la fauna Uruguaya, con descripción de nuevas especies. Bol. Inst. Oceanogr., São Paulo, 4 (1, 2): 3-80.

DUARTE, L.C.; F.J. VonzUBEn \& S.F. ReIS. 1998. Orthogonal projections and bootstrap resampling procedures in the study of inf raspecific variation. Gen. Mol. Biol. 21 (4): 479-486.

DYER, B.S. 1996. Phylogenetic revision of Atherinopsinae (Teleostei, Atherinopsidae), with comments on the systematics of the south american freswater fish genus Basilichthys Girard. Miscellaneous 
Publications, Mus. Zool. Univ. Michigan (185): 1-64.

EvermanN, B.W. \& W.C. Kendall. 1906. Notes on a collections of fishes from Argentina, South America, with descriptions of three new species. Proc. U.S. Nat. Mus. 31 (1482): 67-108.

GodoI, M.P. DE. 1946. Contribuição a biologia d o peixe-rei Odontesthes bonariensis. Rev. B rasil. Biol. 6 (3): $373-384$.

JENYNS, L. 1842. The Zoology of the voyage on H.M.S. Beagle, under the Command by Captain Fitzroy,

R.N. during the years 1832 to 1836 (Edited and superintended by Charles Darwin). London Fish 4: $1-172$.

Jolicoeur, P. 1963. The multivariate generalization of the allometry equation. Biometrics 19: 497-499. Jolicoeur, P. \& J.E. Mosimann. 1960. Size and shape variation in the painted turtle. A principai componente analysis. Growth 24 (4): 339-354.

JORDAN, D.S. \& C.L. HuBBS. 1919. Studies in Ichthyology - A monographic review of the family of Atherinidae or silversides. Stanf ord, Univ. Publ. Biol. Sci., 87p.

Kleerekoper, H. 1945. O peixe-rei. Rio de Janeiro, Ministério da Agricultura, 98p.

Lahille, F. 1929. El pejerrey. Bol. Min. Agric., Buenos Aires, 28 (3): 261-395.

Marcus, L.F. 1990. Traditional morphometrics. Proc. Michigan Morphometrics Workshop, Special Publication, (2): 77-122.

Marrero, A. 1950. Flechas de Plata. Atherinidos argentinos pejerreys y laterinos. Buenos Aires, Ed. Breitman, 157p.

Miranda Ribeiro, A. DE. 1915. Fauna brasiliense: peixes. (Eleutherobrânquios Aspirophoros). Physoclisti. Arch. Mus. Nac., Rio de Janeiro, 5 (não paginado).

MoRriSON, D.F. 1976. Multivariate statistical methods. New York, McGraw-Hill, $2^{\text {nd }}$ ed., $415 p$.

Mosimann, J.E. \& F.C. James. 1979. New statistical methods for allometry with application to Florida red-winged blackbirds. Evolution 33 (1): 444-459.

NeFF, N.A. \& L.F. MARCUS. 1980. A survey of multivariate methods for systematics. NewYork, Privately published, 234p.

Pimentel, R.A. 1979. Morphometrics. The multivariate analyses of biological data. Dubuque, Kendall/Hunt Pub., 276p.

Prodohl, P.A. \& J.S. Levy. 1989. Genetic study of Atherinidaef ishes of Mangueira Lagoon(RS-Brazil). Comp. Biochem. Physiol., 94B (3): 423-426.

REIS, S.F. DOS. 1988. Morfometria e estatistica multivariada em biologia evolutiva. Revta bras. Zool. 5 (4): $571-580$.

REIS, S.F. dos; R.A. DA Cunha; J.C.Garavello \& A.S. ABE. 1987. Discriminação pela forma em relação ao tamanho: um exemplo com peixes do gênero Leporinus. Ci. Cult. 39 (8):757-761.

Reyment, R.A.; R.E. Blackith; N.A. CAmpbell. 1984. Multivariate morphometrics. London, Academic Press, 2.ed., 233p.

Risso, E.N.P. \& F.J.J. Risso. 1953. El cornalito Sorgentinia incisa (Jenyns) n.g. y su ubicación sistemática (Atherinidae, Sorgentininae nueva subf amilia). Trabajo del Mus. Três Arroyos, (I): $1-25$.

RohlF, F.J. 1990. Morphometrics. Ann. Rev. Ecol. Syst 21: 299-316.

1994. NTSYS-pc. Numerical taxonomy and multivariate analysis system. Version 1.80. New York, Department of Ecology and Evolution - Stony Brook.

RohlF, F.J. \& F.L. Bookstein. 1987. A comment on shearing as a method for "size correction". Syst. Zool. 36 (4): 356-367.

SAEED, B.; W. IVANTSOFF \& L.E.L.M. CrowLEY. 1994. Systematic relationships of Atheriniform families within Division I of the Series Atherinomorpha (Acanthopterygii) with relevant historical perspectives. Jour. Ichth. 34 (9): 27-72.

SCHULTZ, L.P. 1948. A revision of six subfamilies of Atherine fishes with descriptions of new genera and species. Proc. U.S. Nat. Mus. 98 (3220): I-50.

SokAL, R.R. \& F.J.RohlF. 1981. Biometry. San Francisco, W.H. Freeman, $2^{\text {nd }}$ ed., 859 p.

VAlenciennes, A. 1835. Des Atherines, p. 348-354. In: G. Cuvier \& A. Valenciennes (Ed.). Histoire 
Naturelle des Poissons. Paris, vol. 10, 358p.

VILLwock, J.A. 1984. Geology of the coastal province of Rio Grande do Sul, southem Brazil: A syntesis. Pesquisas, Porto Alegre, 16: 5-50.

VILLwock, J.A. 1987. Processoscosteiros e a formação das praias arenosas e campos de dunas ao longo da costa sul e sudeste brasileira. In: Anais Simpósio Ecossistemas da Costa Sul e Sudeste Brasileira: síntese dos conhecimentos, Cananéia, p. 380-398.

. 1988. Geologia e recursos minerais da Província Costeira do Rio Grande do Sul. In: Anais Encontro Geológico-Mineiro do Rio Grande do Sul, Porto Alegre. p. 83-98.

WHITE, B.N. 1985. Evolutionary relätionships of the Atherinopsinae (Pisces: Atherinidae). Contrib. Sci. (368): 1-20.

Recebido em 10.VIII.2000; aceito em 04.1II.2002. 